\title{
7. DEFORMATION STRUCTURES AND FLUID FLOW IN THE TOE REGION OF THE NANKAI ACCRETIONARY PRISM ${ }^{1}$
}

\author{
Timothy Byrne, ${ }^{2}$ Alex Maltman, ${ }^{3}$ Emma Stephenson, ${ }^{3}$ Wonn Soh, ${ }^{4}$ and Rob Knipe ${ }^{5}$
}

\begin{abstract}
This paper presents results of an interdisciplinary investigation of the relation between fluids, fluid flow, and deformation in the toe region of the Nankai accretionary prism. The techniques include thin-section petrography, SEM, TEM and microprobe analyses, and X-ray computed tomography as well as laboratory experiments. Together, the data suggest three structural/hydrologic regimes within the prism. These are: (1) the accreting sediments above the décollement zone, (2) the décollement zone, and (3) the underthrust sediments. The regime above the décollement is characterized by sediments that are progressively dewatered through both a penetrative fabric and a pervasive, but apparently poorly interconnected, set of core-scale deformation structures. The décollement is characterized by a relatively high density of structures/meter and is considered to be a regime of low stress but frequent failure. Hydrologically the décollement retards the vertical flow of fluids and enhances the potential for overpressuring in the footwall. Finally, the footwall regime contains very few tectonic structures and is structurally isolated from the stresses related to plate convergence. This regime provides an important component to the tectonics of the Nankai prism, however, because it supplies the overpressured fluids that cause the décollement to fail at relatively low shear stresses.
\end{abstract}

\section{INTRODUCTION}

Convergent boundaries represent one of the most active tectonic environments on earth. In submarine environments, these plate boundaries are also sites where water-charged and easily deformed sediments become progressively consolidated and dewatered. In the past few years it has become widely recognized that these escaping fluids play an important role in influencing the morphology and dynamics of submarine accretionary prisms. The detailed relation between dewatering, fluid flow, and deformation, however, remains only poorly understood. In fact, it is still debated as to whether deformation assists or impedes dewatering (Karig, 1986; Arch and Maltman, 1990). More specifically, some studies have suggested that deformation structures can act as conduits for fluid flow and increase the bulk permeability (Carson and Berglund, 1986; Moore and BijuDuval, 1984), whereas other studies have suggested the opposite.

In this paper we report several new lines of evidence that suggest deformation plays a significant, but still poorly understood, role in the behavior of fluid flow in an active accretionary prism. The new data and observations come primarily from material recovered during the drilling of Site 808 of ODPLeg 131 in the toe region of the Nankai accretionary prism (Figs. 1 and 2). The approaches used include core-scale and optical microscope examination of structures, scanning and transmission electron microscopy, computed tomographic imagery, monitoring of the coupling between permeability and deformation in the laboratory, and limited geochemical analyses.

The results presented below suggest an intimate relation between dewatering and deformation. Specifically, the results suggest two main conclusions: (1) The pervasive deformation structures present in the Nankai accretionary prism, primarily small faults and kink-like structures, acted as localized zones of dewatering. Although the contribution of these structures individually to the dewatering history of the prism is inferred to be relatively limited because there is very

\footnotetext{
${ }^{1}$ Hill, L.A., Taira, A., Firth, J.V., et al., 1993. Proc. ODP, Sci. Results, 131: College Station, TX (Ocean Drilling Program).

${ }^{2}$ Department of Geology and Geophysics, University of Connecticut, Storrs, CT 06269, U.S.A.

${ }^{3}$ Institute of Earth Studies, The University College of Wales, Aberystwyth, SY23 3DB, United Kingdom.

${ }^{4}$ Institute of Geosciences, Shizuoka University, Shizuoka, 422 Japan.

${ }^{5}$ Department of Earth Sciences, University of Leeds, Leeds LS2 9JT, United
} Kingdom. little evidence that fluids were channelized along the structures, the cumulative effect of these structures could have been considerable. (2) The mesoscopic to submicroscopic character of the décollement zone is substantially different than the character of the deformation structures above the décollement. Based on these differences we interpret the décollement to be a zone of episodic overpressuring and deformation. Evidence for these conclusions is presented below where we have divided the observations from Nankai into three scales of structures: penetrative fabrics, locally developed structures, and structures associated with channelized fluid flow. This is followed by a discussion of the fabrics in the décollement zone. Finally, we summarized results from several laboratory experiments that provide relevant insights to the interaction between deformation and fluid flow.

\section{PENETRATIVE FABRICS AND EVIDENCE FOR DIFFUSIVE DEWATERING}

Two data sets suggest the presence of a tectonically induced penetrative fabric that may have been associated with substantial dewatering of the sediments. The two data sets are: horizontal (transverse to the core axis) compressional wave velocity and low-field magnetic susceptibility. A detailed discussion of the compressionalwave velocity data and results are presented in Taira, Hill, Firth, et al. (1991), while the magnetic susceptibility are presented in Owens (this volume). More recently, we have oriented the horizontal velocity data using magnetic remanence directions. We also review the relevant aspects of the magnetic susceptibility data.

Compressional velocities were measured at approximately $70-\mathrm{cm}$ intervals in two directions: parallel (or longitudinal) and perpendicular (or transverse) to the axis of the core barrel. These data, by themselves, allow for the calculation of the acoustic anisotropy of the sediments and Taira, Hill, Firth, et al. (1991) report anisotropies of between $5 \%$ and $10 \%$ for the sediments above the décollement. The orientation of the anisotropy in a horizontal plane is unconstrained, however, because all of the samples were rotated about a vertical axis during drilling.

To correct for this drilling-induced rotation we applied a "paleomagnetic correction" to each velocity measurement based on a mean declination value as determined from the magnetic remanence of the cores. This correction was possible because the transverse velocity measurements were routinely made in the same orientation relative to a mark on the core liner (a double line parallel to the core axis). 


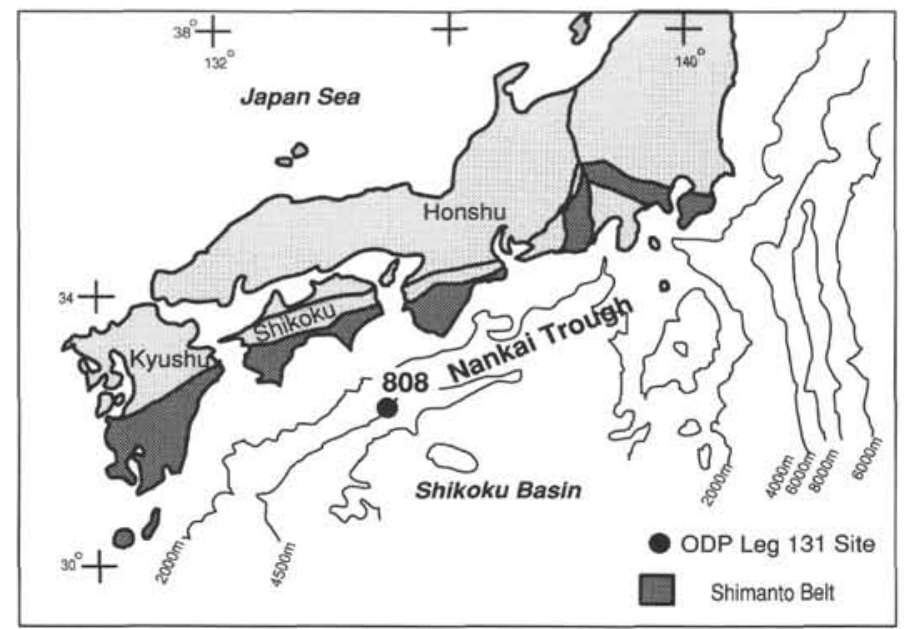

Figure 1. Regional-scale map showing Japan and the location of Site 808.

This mark was also used as a reference for paleomagnetic and structural measurements.

In orienting the velocity data we first examined both the natural remanent magnetization and the magnetic remanence after alternating field demagnetization over a $10-$ to $30-\mathrm{cm}$ interval that included the site sampled for transverse velocity (see Taira, Hill, Firth, et al., 1991, for discussion of shipboard paleomagnetic techniques and results). If the paleomagnetic remanence was relatively stable (i.e., consistent in declination, inclination and intensity) over this 10 - to $30-\mathrm{cm}$ interval, the mean declination for the interval was calculated and used to determine the true orientation of the transverse velocity data. In total, approximate 350 velocity and paleomagnetic poles from nearly $500 \mathrm{~m}$ of section (from 609 to $1128 \mathrm{mbsf}$ ) are represented in Figure 3 . About $2 / 3$ of the data are from above the décollement.

We also attempted to account for variations velocities due to changes in lithologies by including in Figure 3 only samples that were described as homogeneous silty clay. This eliminated most of the relatively coarse-grained turbidites in the upper section of Site 808. We also eliminated velocity data from a $50-\mathrm{m}$ interval between 778 and 823 mbsf that contained an unusually large number of high velocities (Taira, Hill, Firth, et al., 1991). This interval also contained an unusually high concentration of faults and several carbonate horizons as well as the only clastic dike and hydrofracture observed at Site 808. Finally, to construct Figure 3, we binned the velocity data over $10^{\circ}$ intervals and then calculated the best-fitting function for the binned data (see also Bamford and Nunn, 1979).

There is a clear difference in pattern of horizontal velocities above and below the décollement (Fig. 3). Above the décollement the velocity data show a peak of about $2200 \mathrm{~km} / \mathrm{s}$ that trends generally northeast. There is also a well-developed low in the velocity data approximately $90^{\circ}$ from the velocity maximum. The velocity maximum and minimum are perpendicular and parallel, respectively, to the inferred direction of plate convergence (about $310^{\circ}$ to $315^{\circ}$, Lallemant et al., this volume).

Although the coincidence of the directions of velocity anisotropy and the plate convergence vectors suggest a tectonic origin, a specific origin for the anisotropy is unknown at present. For example, the anisotropy may reflect the reorientation of detrital and/or diagenetic phyllosilicates resulting from penetrative shortening (e.g., Taira and Niitsuma, 1985). Alternatively, the fabric may reflect the presence of pervasive microcracks that may have formed after the sediments were retrieved. These two interpretations, however, can be tested with magnetic susceptibility data because these data are insensitive to the presence of microcracks, as discussed in Owens (this volume).

The magnetic susceptibility data show two very different patterns above and below the décollement (see Owens, this volume; Byrne et al., this volume). Above the décollement susceptibility minima lie close to the poles of bedding, and the maxima are horizontal and trend northeast. The fabric ellipsoid is also clearly triaxial. Below the décollement, the susceptibility minima are perpendicular to bedding, as they are above the décollement. The susceptibility maxima, however, are scattered, and the fabric ellipsoid is clearly oblate. Owens (this volume) considers the triaxial susceptibility ellipsoid above the décollement to be a result of the modification in initial bedding/compaction grain fabric by northwest-directed shortening. Presumably this fabric also accounts for the anisotropy recognized in the horizontal velocity data (Fig. 3). The oblate susceptibility ellipsoids below the décollement are consistent with fabrics that form during vertical loading and gravitationally induced consolidation. Based on the difference between the grain fabric above and below the décollement and theoretical modeling by Graham (1966), Owens (pers. comm., 1992) estimates the amount of shortening above the décollement to be about $10 \%$.

Owens (this volume) also shows that the magnetic fabric formed relatively early in the history of accretion because the grain fabrics are folded and deformed by the footwall syncline below the frontal thrust. Byrne et al. (this volume) also argued for early formation of the magnetic fabric based on a correlation of some of the fabrics with a suite of mesoscopic scale structures known to have formed early in the history of accretion. The early formation of the grain fabrics raises an important question concerning the relation between this fabric and dewatering of the Nankai prism: was this deformation constant volume or was it associated with dewatering and consolidation? Considering the poorly consolidated state of the Nankai sediments and their high porosities $(30 \%-50 \%$, which are minimum initial values), it seems likely that some pore volume (probably on the order of $10 \%$ ) may have been lost as the fabrics developed. Because the fabric is penetrative at a microscopic scale, the volume loss must have occurred through a network of interconnected pore spaces.

Alternatively, northwest-directed shortening may have been constant volume and accommodated by vertical thickening or alongstrike extension. Although we are not aware of data that indicate along-strike extension, Karig and Lundberg (1990) have proposed vertical thickening of the protothrust zone (i.e., the area seaward of the frontal thrust) of the Nankai prism southwest of Site 808 . Based on the change in angle of early kink-like structures these authors proposed a strain ratio of up to 2.5 . Assuming a constant volume deformation, this strain ratio corresponds to a vertical extension of approximately $60 \%$ (and horizontal shortening of $40 \%$ ) which is significantly higher than estimates of the vertical strain associated with the grain fabric. The presence of even a small magnitude of penetrative vertical extension (i.e., on the order of $10 \%$ ) in the protothrust zone, however, would suggest that the grain fabrics recorded by the magnetic and velocity data formed during constant volume. These two interpretations (i.e., constant volume vs. volume loss) can be more fully evaluated with a better understanding of the relative importance of penetrative vs. localized thickening mechanisms.

\section{LOCALIZED DEWATERING AND CONSOLIDATION}

The correlation between the distribution of small faults and overconsolidation provides one of the most striking suggestions that the structural features are associated with dewatering of the Nankai sedimentary sequence (see Taira, Hill, Firth, et al., 1991; Byrne, this volume). The specific relation between deformation and dewatering is not straightforward, however, because the interval of overconsolidation (essentially the entire sedimentary sequence above the décollement) also correlates with the presence of a penetrative deformation fabric as discussed above. Moreover, it is not clear when the overconsolidation occurred - early in the accretion history when the penetrative fabric formed (i.e., the volume loss model discussed above) or late in the history when the small faults formed. Consequently, in the following paragraphs we focus only on the possible evidence for 

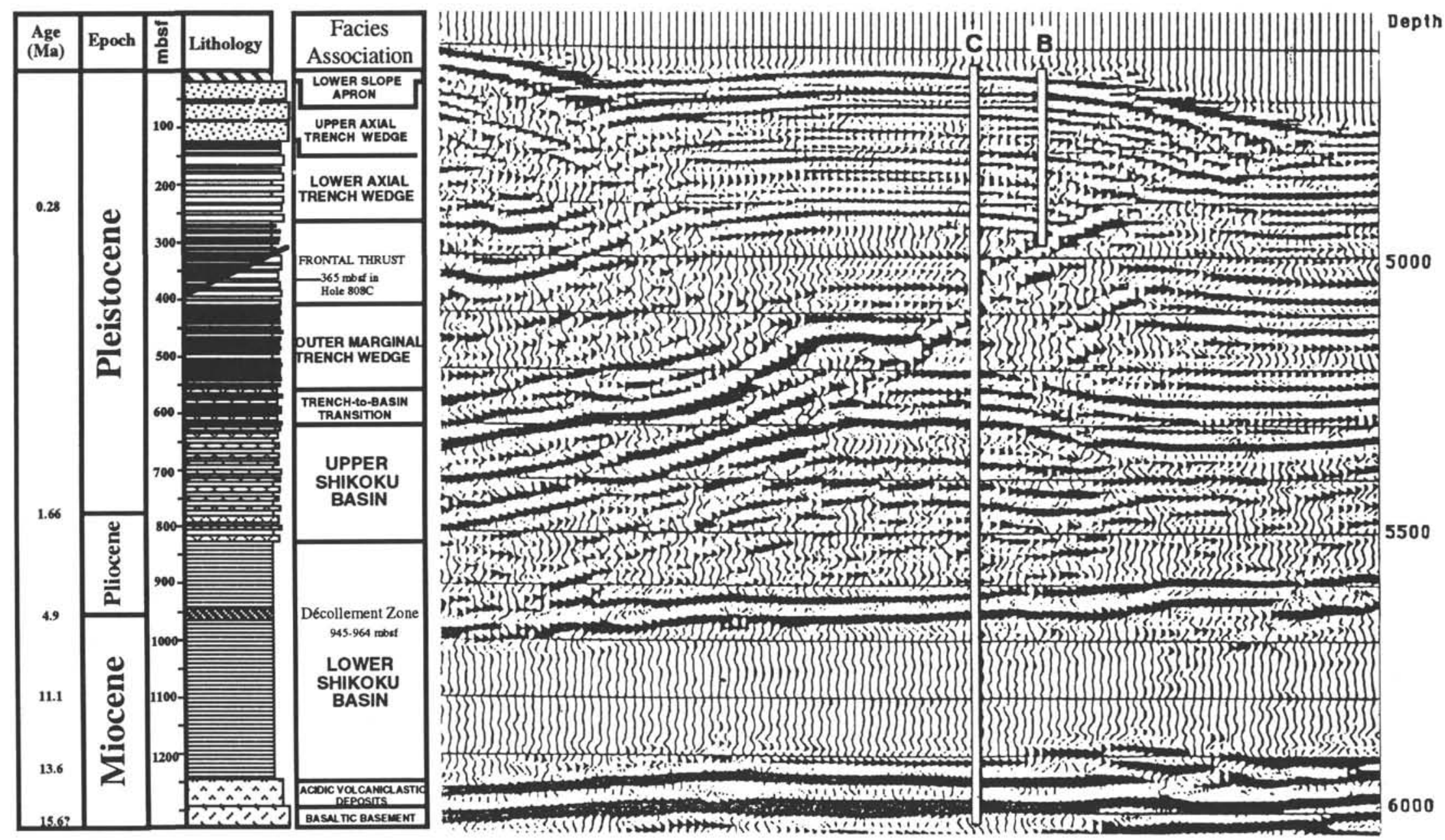

Figure 2. Seismic reflection profile (from Moore et al., 1990) and stratigraphic column and lithofacies (from Taira, Hill, Firth, et al., 1991) for ODP Site 808. Positions of Holes 808B and 808C are shown on the seismic profile; Holes 808A, 808D, and 808E, although not shown, are within a few hundred meters of Holes 808B and 808C. See Taira, Hill, Firth, et al. (1991) for description of the stratigraphic column. Note in the seismic profile the well-developed polarity reversal (relative to the first reflection at the seafloor) at the level of the décollement (depth in meters below sea level). This reversal dies out about $8 \mathrm{~km}$ seaward of the deformation front (Moore et al., 1990). 

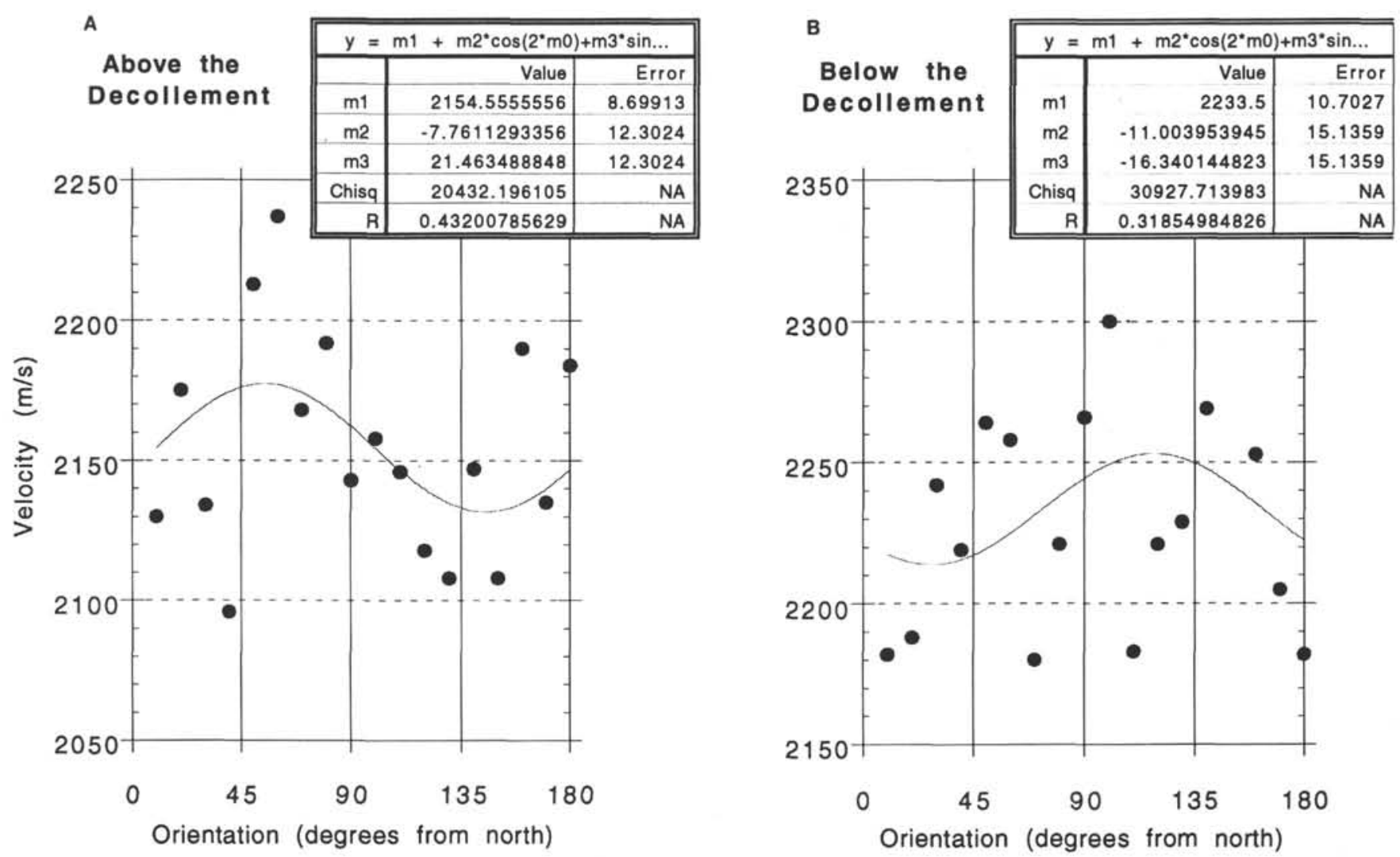

Figure 3. Velocity scattergram showing the variation in velocity vs. orientation. A. Oriented velocity data above the décollement. Note well-developed peak in velocity in the data above the décollement with a trend of about $\mathrm{N} 50^{\circ} \mathrm{E}$ and the corresponding velocity low at about $\mathrm{N} 40^{\circ} \mathrm{W}$. This azimuthal variation in velocity corresponds to a horizontal velocity anisotropy of about $2 \%$. B. In contrast, a well developed velocity anisotropy does not appear to be present in the sediments below the décollement.

consolidation and dewatering within individual deformation structures. To this end, we first review the microscopic texture and geometry of the dominant deformation structures. This is followed by discussion of the bulk density of the sediment within these structures based on computed tomography data. The possible relation between the individual structures and dewatering of the matrix is discussed at the end of the paper.

\section{Microscopic Character and Internal Fabric Geometries}

Detailed core- and microscopic-scale studies of the deformation structures at Site 808 suggest three dominant types of structures: kink-like bands, small fault zones, and scaly clay or scaly breccia zones. Maltman et al. (this volume) present a detailed description of these structures as well as a slightly different division of the dominant structures and Byrne et al. (this volume) summarizes the correlation of the different structures with magnetic, velocity, and physical property data. We also include descriptions of a typical kink-like band and small fault in this paper to emphasize the possible relation of these structures to consolidation.

Kink-like deformation bands are the oldest and second most abundant structure recognized at Site 808 (Maltman et al., this volume; Taira, Hill, Firth, et al., 1991). Macroscopically they are diffusely bounded zones that are slightly darker than the surrounding material, but they are rarely as dark as the small faults (Maltman et al., this volume). The bands are commonly $1-2 \mathrm{~mm}$ in cross-sectional width (e.g., Fig. 4), although some examples reach 1 to $2 \mathrm{~cm}$ (e.g., Pl. 2, Fig. 1). The bands typically offset adjacent marker horizons (e.g., bedding) although displacements, where documented, are relatively small ( $<$ a few millimeters) even when the bands are relatively wide and well developed. All of the documented displacements record contractional strains relative to bedding.

In three dimensions the bands form relatively simple conjugate sets that are centered on bedding and have a dihedral angle of about $45^{\circ}$ (Maltman et al., this volume). When corrected with paleomagnetic data for rotations due to drilling, the kink-like structures strike northeast and dip either northwest or southeast. We therefore have inferred that the shortening direction associated with kinks trends northwest, approximately parallel to the plate convergence vector.

At a microscopic scale, the kink-like structures display a substantial amount of substructure and are rarely simply parallel-sided bands with consistently oriented (or deflected) internal fabric (Fig. 4). As shown in Figure 4, the kink-like structures change thickness along their length (dip direction, in this case) and they appear to "pinch" or "swell." Although there is a wide variety of geometries that accommodate this apparent pinching and swelling, the pinched areas are all essentially normal faults relative to the boundaries of the kink-like bands. These normal faults occur at a low angle to the bands (approximately $15^{\circ}$ ) and display a phyllosilicate fabric that is much more concentrated and well developed than the fabrics within or external to the kink-like structure (Fig. 4). The normal fault substructures have geometries and kinematics consistent with Riedel $\mathrm{R}_{1}$ shears (see also Maltman et al., this volume; Karig and Lundberg, 1990). We therefore consider the Riedel shears to be Mohr-Coulomb instabilities that formed with the kink-like structures.

An aspect of the kink-like structures, including the substructure described below, that may be particularly important for the hydrology of the sediments is that all of the structures appear to have intensified or concentrated the primary phyllosilicate fabric within the bands. This can be seen more quantitatively by comparing the internal and 


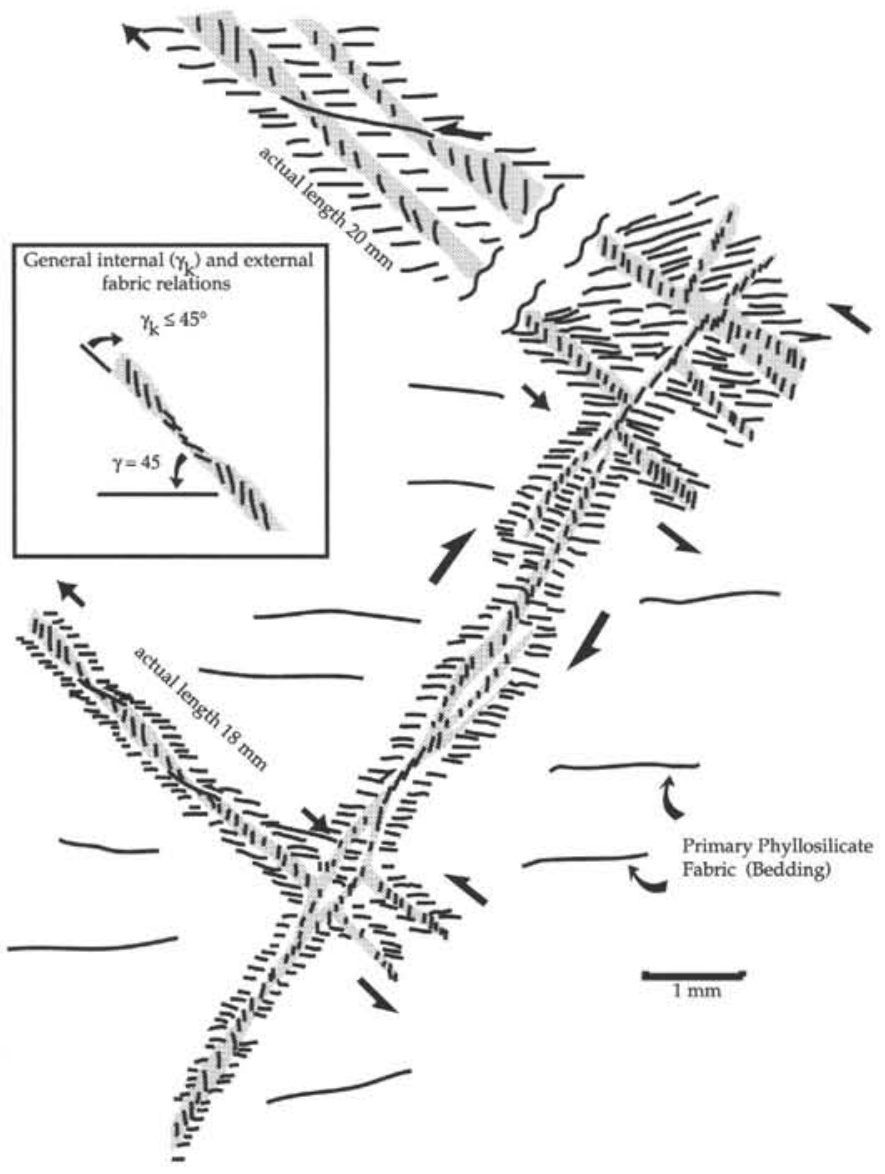

Figure 4. Sketch of photomosaic of three intersecting kink-like structures (Sample 131-808B-24X-3, 92-95 cm). Inset shows general relations of the phyllosilicate fabric inside (internal angle, $\gamma_{\mathrm{k}}$ ) and outside (external angle, l) of the kink band boundary. External angles are consistently about $45^{\circ}$ (see Maltman et al., this volume) whereas internal angles are consistently $\leq 45^{\circ}$.

external angles of the ODP kink-like structures to similar angles in more classic kink bands (Fig. 5). The ODP structures have a generally constant external angle $\left(\gamma=45^{\circ}\right)$ but a highly variable internal angle $\left(\gamma_{k} \leq 45^{\circ}\right)$ which, in part, reflects the development of the Riedel shears described above. The relatively low internal angles for the ODP kink-like structures indicate a decrease in volume for these structures (Fig. 5) which is consistent with the relatively intense phyllosilicate fabric in these zone. Computer tomographic X-ray data, summarized below, also indicate a decrease in volume within these zones.

In contrast to the kink-like structures, the small faults are typically narrow $(<1 \mathrm{~mm})$, sharply bounded zones of displacement that appear much darker than either the kink-like structures or the surrounding sediments (Pl. 1; Taira, Hill, Firth, et al., 1991; Maltman et al., this volume). Small faults are present throughout Site 808 , but they are particularly concentrated between the frontal thrust and the décollement. At the scale of the core barrel, the faults extend for several centimeters and record displacements of a few to $<7 \mathrm{~mm}$. The fault surfaces have a polished appearance to various degrees, and are commonly lineated. The lineations, or slickenlines, consist of fine grooves or slightly broader undulations that trend parallel to the slip direction of the fault zone.

In three dimensions, the faults are more complex than the kink-like structures. In general the faults dip moderately to gently with wide variations in strike, resulting in a generally low-dipping fabric composed of a web of intersecting faults. In some cases, the faults form conjugate sets, and Lallemant et al. (this volume) have recognized a change in the dihedral angle of different conjugate angles with depth. These authors have proposed that this change reflects a decrease in the coefficient of friction angles with depth.

At a microscopic scale the small faults are characterized by thin to thick zones of very well developed phyllosilicate fabric that roughly parallels the fault zone boundary. One of the best examples of the small faults is from the frontal thrust (Pl. 1). In this example, the fault zone is composed of strongly reoriented phyllosilicates as well as a few lens-shaped remnants of moderately deformed matrix(?). Although many of the phyllosilicates within the zone are subparallel to the zone boundaries, there is also a secondary fabric that is equally pervasive but inclined at a low-angle to the zone boundaries. This fabric is highlighted in Plate 1 and has a geometry that is consistent with Riedel shears. There are also a series of Riedel-like normal faults that separate the lens-shaped remnants. In total, the well developed phyllosilicate fabrics within these faults suggest substantial consolidation relative to the surrounding, less deformed sediments. Consolidation and dewatering of the small faults is also indicated by X-ray tomography studies.

\section{Computed Tomographic X-ray Scans}

To define more precisely the three-dimensional image and to document the density structure of the deformational structures in the Nankai sediments, we scanned and computed X-ray tomographic images of 21 ODP samples (Table 1). The samples included 18 mudstones, 2 greenstones, and 1 silty mudstone intercalated with green tuffaceous layers. One acrylic material was scanned as a standard. Of the 21 samples approximately half were whole-round cores, ranging from $5 \mathrm{~cm}$ to $45 \mathrm{~cm}$ long, that were coated with a thin film of paraffin soon after collection. The remaining samples were relatively small chips collected for fabric analysis. In total, about 150 tomographic images were constructed.

Computed tomography (CT) X-ray scanning is based on the mathematical theorem that relates multiple X-ray projection directions to a two- or three-dimensional image of an object (see also Soh et al., this volume). During data collection X-rays are absorbed and scattered by the sample and the attenuation coefficient of the object is determined. Simply, an X-ray beam of intensity Io yields a linear attenuated intensity $I$ as a result of passing through a sample of material with thickness $D$. This relation can be expressed as:

$$
I=I_{o} \exp (-\mu D)
$$

where $\mu$ is the linear attenuation coefficient.

In this study, linear attenuation coefficients were measured as the sample was rotated through $180^{\circ}$ at $15^{\circ}$ increments. A two-dimensional map was then constructed with the aid of a computer, and the resulting map, or tomographic image, was projected on a color monitor. In these images areas of relatively high linear attenuation, coefficients are brighter than areas with low coefficients (e.g., Pl. 2, Figs. 2 and 4). Higher attenuation coefficients also correlate with high densities, as discussed below. Hard copies of the these images of relative attenuation coefficients (or density) were made with a Polaroid camera.

The CT scanning system used in this study is Toshiba TOSCANNER 23201(or JACK-320) that is housed in the Technology Research Center of the Japan National Oil Corporation, Chiba Prefecture, Japan. The JACK-320 computer also converts the linear attenuation coefficients into numerical "CT values" following this relation:

$$
\text { CT value }{ }_{(\mathrm{JACK} 320)}=250\left(\mu_{\text {sample }}-\mu \text { water }\right) / \mu \text { water }
$$

where $\mu_{\text {sample }}$ is the linear attenuation coefficient of the material with a unit volume during a scan, and $\mu$ water is the attenuation coefficient of a reference material (water) occupying the same volume during a 


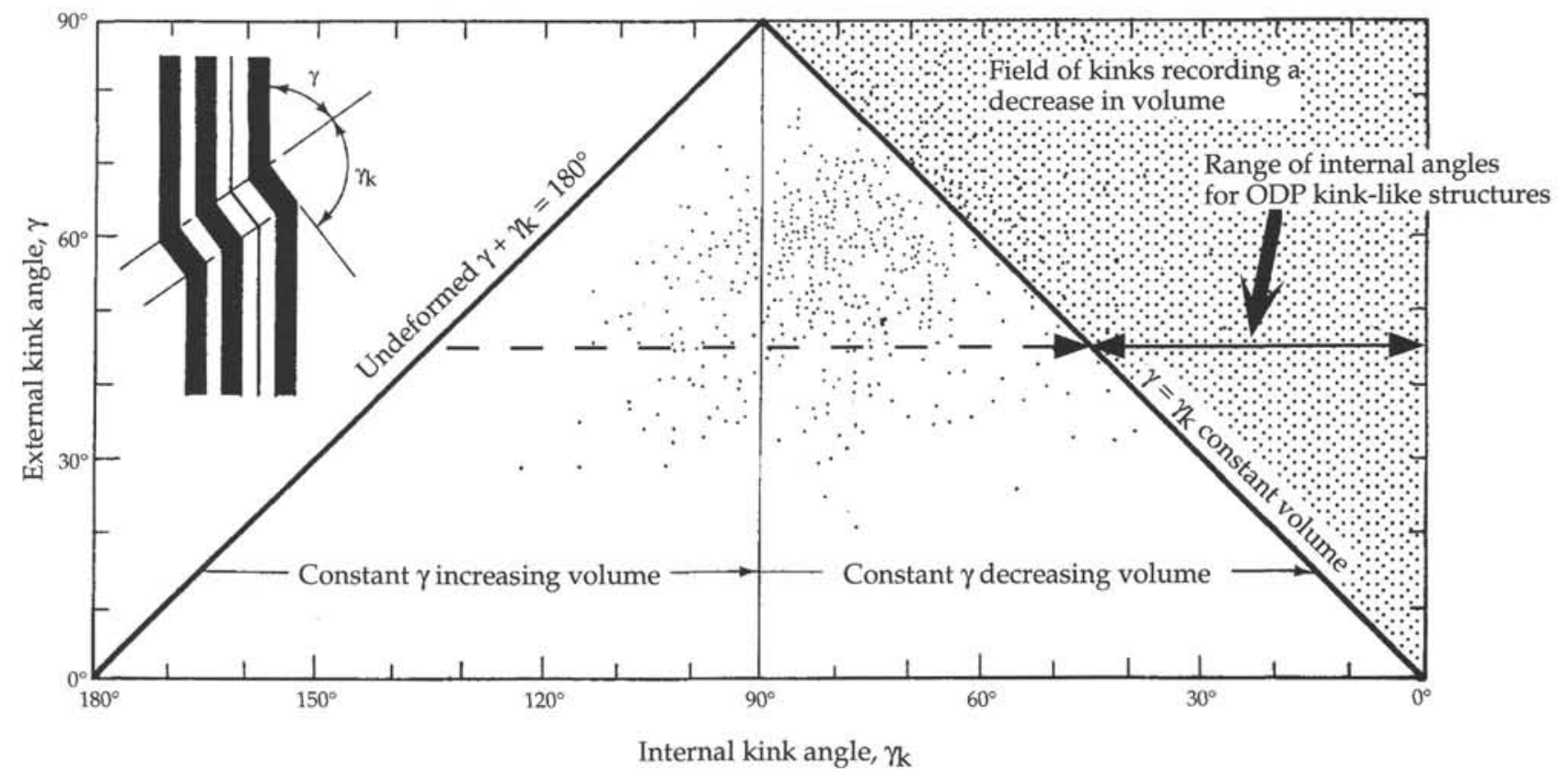

Figure 5. Diagram showing all possible relations between internal and external angles in kink bands (after Suppe, 1985). Dots are internal and external angles for several hundred kinks in Ireland (Anderson, 1968) and appear to be typical of many around the world (Suppe, 1985). The horizontal line (i.e., constant external angle) with double arrows in the field of volume decrease shows the range of internal angles in the kink-like structures from Site 808. That is, in general the kink-like structures record a decrease in volume during deformation. The dashed horizontal line shows the inferred deformation path of the kink-like structures from Site 808 .

calibration scan. Here, $\mu$ water can be estimated as $0.137 \mathrm{~cm}^{2} / \mathrm{g}$, assuming that the actual radiation energy is $200 \mathrm{kV}$ (about $65 \%$ of the peak energy) (cf. Soh et al., this volume). These data are tabulated for each image pixel (minimum pixel size for scan is $0.15 \mathrm{~mm}$ ) and are saved to either a hard or floppy disk. One image typically consumes about $1 \mathrm{Mb}$ of memory.

\section{Results}

One of the most important results of the CT analysis is the correlation between linear attenuation coefficients and the bulk density $\rho$ for the Leg 131 samples (Fig. 6). This relation can be expressed as:

$$
\rho_{\text {sample }}=0.486+4.83 \mu_{\text {sample }}\left(r^{2}=0.80\right)
$$

The regression line for these data crosses the $1.0 \mathrm{~cm}^{3} / \mathrm{g}$ density value at a minimum attenuation value of $0.137 \mathrm{~cm}^{2} / \mathrm{g}$ which is the value of the water standard. Other physical properties of the samples (measured on board, see Taira, Hill, Firth, et al., 1991), such as porosity, water content, and depth show similar but less well-defined linear correlations.

Plate 2 shows the relation between variations in linear attenuation coefficients and specific structural features in more detail. The close correlation between the bright areas in the CT scans and the individual faults or kink-like bands indicates that both types of deformation features are zones of relatively high density.

We were also able to obtain attenuation coefficients for eight zones of deformation (Table 1 and Fig. 6) and all of the values are higher than the associated matrix values, consistent with the qualitative observations (Pl. 2). The differences in coefficients between the deformation zone and matrix for these eight samples range from 0.021 to $0.038 \mathrm{~cm}^{2} / \mathrm{g}$ with some of the highest values (e.g., $0.038 \mathrm{~cm}^{2} / \mathrm{g}$ and $0.035 \mathrm{~cm}^{2} / \mathrm{g}$ ) coming from sediments in the frontal thrust zone. Based on equation (3) this range in coefficient values corresponds to density changes ranging from 0.11 to $0.22 \mathrm{~g} / \mathrm{cm}^{3}$. The highest attenuation coefficient, however, comes from the sample from the décollement zone ( $808 \mathrm{C}-69 \mathrm{R}-2,72-74 \mathrm{~cm})$ which is known independently to have an anomalously high density (Taira, Hill, Firth, et al., 1991).

There are two possible interpretations for the increase in the CT attenuation coefficients within the deformation structures. First, the CT attenuation coefficients can be related to concentration of elements with relatively high atomic numbers, such as Fe. Enrichment of Fe within the faults and bands may have occurred as result of the fluid flow and precipitation during or after deformation. Roughly, a minimum enrichment of only $0.4 \mathrm{wt} \%$ in pyrite content relative to the matrix is needed to increase the CT values to those we have measured (cf. fig. 6 in Anderson et al., 1988). Second, the increase in linear attenuation coefficients may be related to a decrease in porosity. Based on the relations between the linear attenuation coefficients and density and the density-porosity relation of

$$
\text { porosity }=171.544-62.798 \rho_{\text {sample }}\left(r^{2}=0.899\right)
$$

a porosity reduction of ranging from approximately $6 \%$ for the deformation bands to $13 \%$ for the faults relative to the undeformed matrix can be calculated.

In summary, the $\mathrm{CT}$ scanning method produces a nondestructive cross-sectional image of the deformed sediments. Areas of increased attenuation correlate with an increase in bulk density. Although there is some degree of uncertainty in these results, the CT technique yields consistent results and suggests that the faults and shear zones are more dense than the surrounding matrix. We have proposed two explanations for this increase in bulk density: a decrease in porosity, a concentration of elements with high atomic numbers, or both. At present, however, most of the available data suggest porosity reduction is the dominant densification process.

\section{EVIDENCE FOR CHANNELIZED DEWATERING}

Relatively clear evidence for at least minor channelized dewatering of Site 808 sediments is provided by three sets of observations all of which come from about 800 mbsf. These observations include: a 
Table 1. Summary of CT values, attenuation coefficients, depth, density, and porosity data for the 21 samples analyzed with X-ray tomography.

\begin{tabular}{|c|c|c|c|c|c|c|c|c|c|c|}
\hline Sample No. & $\begin{array}{l}\text { Hole, core, section, } \\
\text { interval }(\mathrm{cm})\end{array}$ & $\begin{array}{l}\text { Sample } \\
\text { CT value }\end{array}$ & $\begin{array}{l}\text { Deformation } \\
\text { CT value }\end{array}$ & $\begin{array}{l}\text { Attenuation } \\
\left(\mathrm{cm}^{2} / \mathrm{g}\right)\end{array}$ & $\begin{array}{l}\text { Def. zone } \\
\text { atten. } \\
\left(\mathrm{cm}^{2} / \mathrm{g}\right)\end{array}$ & $\begin{array}{c}\text { Atten. } \\
\text { difference } \\
\left(\mathrm{cm}^{2} / \mathrm{g}\right)\end{array}$ & $\begin{array}{l}\text { Depth } \\
\text { (mbsf) }\end{array}$ & $\begin{array}{l}\text { Density } \\
\left(\mathrm{g} / \mathrm{cm}^{3}\right)\end{array}$ & $\begin{array}{c}\text { Porosity } \\
(\% 0) \\
\text { (\%o dry wt) }\end{array}$ & $\begin{array}{l}\text { Water } \\
\text { content }\end{array}$ \\
\hline 1 & $808 \mathrm{~A}-5 \mathrm{H}-6$ & 274 & & 0.287 & & & 43.20 & 1.77 & 60.4 & 53.73 \\
\hline 2 & $808 \mathrm{~B}-17 \mathrm{X}-2,39-44$ & 257 & & 0.278 & & & 265.38 & 1.82 & 44.8 & 33.67 \\
\hline 3 & $808 \mathrm{~B}-17 \mathrm{X}-4,41-47$ & 349 & 418 & 0.328 & 0.366 & 0.038 & 268.34 & 2.00 & 42.6 & 27.54 \\
\hline 4 & $808 C-1 R-1,95-97$ & 345 & 383 & 0.326 & 0.347 & 0.021 & 299.48 & 1.97 & 46.3 & 29.92 \\
\hline 5 & $808 \mathrm{~B}-24 \mathrm{X}-3,71-74$ & 360 & 407 & 0.334 & 0.36 & 0.026 & 331.00 & 1.99 & 48.6 & 33.38 \\
\hline 6 & $808 \mathrm{C}-6 \mathrm{R}-1,46-50$ & 251 & & 0.275 & & & 347.00 & 1.57 & 32.2 & 26.54 \\
\hline 7 & $808 \mathrm{C}-8 \mathrm{R}-1,112-114$ & 421 & 484 & 0.368 & 0.402 & 0.035 & 367.20 & 2.10 & & \\
\hline 8 & $808 \mathrm{C}-8 \mathrm{R}-3$ & 241 & & 0.269 & & & 369.00 & & & \\
\hline 9 & $808 \mathrm{C}-10 \mathrm{R}-1,20-38$ & 325 & 394 & 0.315 & 0.353 & 0.038 & 386.35 & 2.07 & 40 & \\
\hline 10 & $808 \mathrm{C}-11 \mathrm{R}-2,6-8$ & 319 & 374 & 0.312 & 0.342 & 0.03 & 396.36 & 2.08 & 40.1 & \\
\hline 11 & $808 C-12 R-3,46-49$ & 274 & & 0.287 & & & 408.00 & 2.01 & 45.5 & 30.05 \\
\hline 12 & $808 \mathrm{C}-18 \mathrm{R}-1,148-150$ & 359 & & 0.334 & & & 463.88 & 1.99 & 45.6 & 30.51 \\
\hline 13 & $808 \mathrm{C}-19 \mathrm{R}-3,133-144$ & 223 & 285 & 0.259 & 0.293 & 0.034 & 476.54 & 2.02 & 43.9 & 28.53 \\
\hline 14 & $808 \mathrm{C}-20 \mathrm{R}-5,12-16$ & 251 & & 0.275 & & & 488.00 & 1.99 & 44.6 & 29.8 \\
\hline 15 & $808 \mathrm{C}-25 \mathrm{R}-1,25-32$ & 256 & 309 & 0.277 & 0.306 & 0.029 & 530.25 & 2.00 & 44.7 & 29.63 \\
\hline 16 & $808 \mathrm{C}-44 \mathrm{R}-3,132-135$ & 321 & & 0.313 & & & 716.70 & 2.11 & 37.8 & 22.44 \\
\hline 17 & $808 \mathrm{C}-66 \mathrm{R}-4$ & 475 & & 0.397 & & & 930.00 & 2.23 & 31.9 & 17.17 \\
\hline 18 & $808 \mathrm{C}-69 \mathrm{R}-2,72-74$ & 490 & & 0.406 & & & 956.05 & & & \\
\hline 19 & $808 \mathrm{C}-101 \mathrm{R}-4,81-96$ & 399 & & 0.356 & & & 1257.40 & 2.32 & 26.4 & 13.19 \\
\hline 20 & $808 \mathrm{C}-101 \mathrm{R}-3,120-124$ & 323 & & 0.314 & & & 1256.38 & 2.16 & 30 & 16.58 \\
\hline 21 & $808 \mathrm{C}-102 \mathrm{R}-1,115-120$ & 393 & & 0.352 & & & 1262.60 & 2.23 & 34.4 & 18.53 \\
\hline 22 & acrylic (standard) & 61.33 & & 0.171 & & & & 1.19 & & \\
\hline
\end{tabular}

The columns of data are: $\mathrm{CT}$ value $=$ the $\mathrm{CT}$ value in the matrix, away from the influence of deformation zones; $\mathrm{CT}$ value $=\mathrm{CT}$ values within fault zones or bands: attenuation and Def. zone atten. $=$ attenuation coefficients that correspond to the $\mathrm{CT}$ values shown in the first two columns; atten. difference $=$ the difference between the attenuation coefficients inside and outside the deformation zones. Note the consistently high CT values (and attenuation coefficients) in the deformation zones and the very high CT value from the décollement (Sample 131-808C-69R-2, 72-74 cm).

1.5-cm clastic dike (Taira, Hill, Firth, et al. (1991), a breccia inferred to have formed as a result of hydrofracturing, and quartz/clay-filled veins. Additional, but more indirect, evidence for channelized dewatering is also suggested by limited geochemical data from a one of the small fault zones.

\section{Hydraulic Breccia and Associated Veins}

The material retrieved from between about 787 and 789 mbsf shows core-scale brecciation and unusually steep bedding dips, within a zone of concentrated small faults. At the time of the shipboard descriptions this seemed to be a zone of high strain that failed to register on the seismic section. However, we could not exclude the possibility that the brecciation, at least, was the result of drilling disturbance.

Microscopic examination of samples taken from this interval has demonstrated that the breccia is natural, and almost certainly due to in-situ overpressuring (Maltman et al., this volume). The unsystematic manner in which the faults and shear zones pervade the material contrasts with their typical appearance, and their broadening in places to give patches of breccia (Pl. 3, Fig. 1) has not been observed elsewhere at this site. The fragments of the breccia are markedly angular (Pl. 3, Fig. 2) and have simply "spalled-off" from the wallrock or broken in situ. There is nothing in the orientation of the shape or distribution pattern of the clasts to suggest that the brecciation is the result of tectonic shearing.

The matrix of the breccia varies from being very similar in texture to the fragments, although typically darker in color (PI. 3, Fig. 1), to being composed of a fine-grained siliceous phase. This later material can occur as a very irregular web-like framework for the breccia to well-defined veins (PI. 3, Fig. 2). Microprobe and back-scattering SEM studies suggest that this siliceous, vein-like is composed of intergrowths of very fine-grained silica and clay minerals (Table 2).

The siliceous veins also appear to be associated with a dark halo that is often symmetrically disposed about the veins (PI. 3, Fig. 2). Several chemical transects across these dark zones, however, have yielded only one halo that can be distinguished from the matrix (PI. 3, Fig. 2). This halo contained higher proportions of $\mathrm{Ca}$ and $\mathrm{Fe}$ and appears to be siderite. Most of the halos appear chemically indistinguishable from the matrix. More detailed investigations of the veins and halos are in progress.

In any case, all the observations thus far indicate that this is a "hydraulic breccia," formed not through an increase in deviatoric stress but by in-situ fluid pressures exceeding the strength of the sediment. This is a significant observation because it provides one of the very few clear indications of overpressuring at Site 808. By implication, because the dewatering of the sediments in this interval failed to maintain equilibrium with burial, the drainage of the prism cannot be simple. Although many structural geological observations are more consistent with a pervasive dewatering of the prism rather than channelized flux (Maltman et al., 1991), such drainage must have in places been curbed, with all that entails for reduced material strength.

\section{Microprobe Analyses of the Dark Fault Zones}

To test the possibility that the deformation structures acted as fluid flow conduits, we collected geochemical data across approximately one dozen deformation zones. The data were collected with a wavelength-dispersive microprobe (at Brown University), an energydispersive microprobe (at the University of Connecticut), and an energy-dispersive detector attached to a SEM (at the Museum of Natural History in Japan). Of the 12 samples analyzed, only 1 recorded a change in chemistry across the deformation zone (Fig. 7). This sample is composed of an usually dark and relatively thick fault from the middle of the frontal thrust. At a microscopic scale the dark zone is defined by a band of phyllosilicates that are display a much stronger preferred orientation relatively to the matrix (see, for example, PI. 1). The fault zone is also more reflective than the matrix when viewed in a reflecting light microscope. The chemical transect across this one fault zones shows a jump in the concentration of $\mathrm{Fe}$ at the boundary of the fault zone and generally higher concentration within the fault zone relative to the wall rock (Fig. 7). 

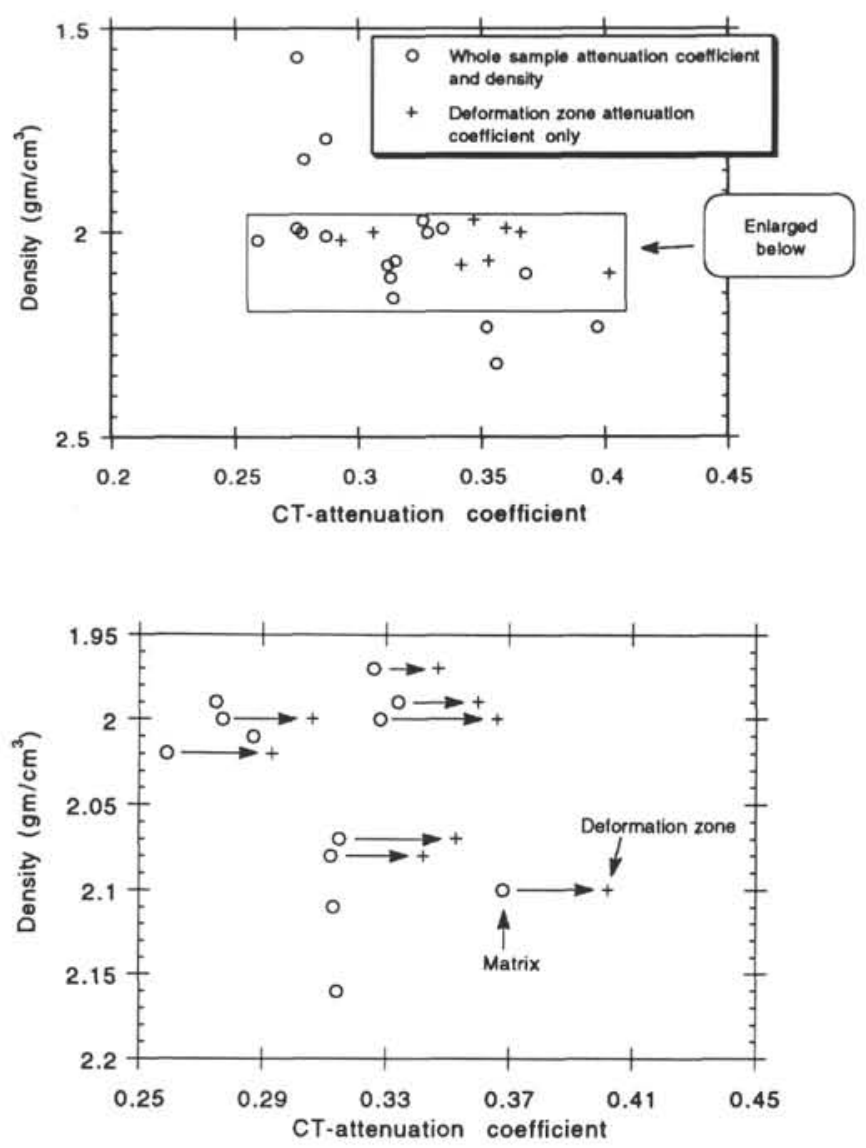

Figure 6. Scatter plot of attenuation coefficients vs. densities for 20 samples from various depths at $S i t e 808$. Attenuation coefficients were determined with a CT X-ray scanner (see text), whereas the densities were measured on the JOIDES Resolution. Typically the density measurements were taken within a few centimeters or a few tens of centimeters of samples used in the CT analysis.

\section{DEFORMATION AND POSSIBLE FLUID FLOW IN THE DÉCOLLEMENT ZONE}

The appearance of the décollement in the cores was reported in Taira, Hill, Firth, et al. (1991), and the lack of obvious evidence for channelized fluid flow was discussed in Maltman et al. (1991). Description of the microstructures is given in Maltman et al. (this volume). Consequently we only emphasize here the aspects of the décollement that may relate to fluid migration.

As summarized by Maltman et al. (this volume) the décollement zone appears to be characterized by a curious mottled or domainal texture at both core- and thin-section-scales (Pl. 4, Figs. 1 and 2). The mottled texture is defined by an irregular and discontinuous set of shear surfaces that surround zones of relatively undeformed silt and clay. The shear surfaces are different than the faults and kink-like bands described above, in Taira, Hill, Firth, et al. (1991) and in Maltman et al. (this volume), in that they are much thinner, more irregular in orientation, and more discontinuous (compare PI. 1 with Pl. 4, Fig. 2). These domains of deformed and undeformed clays are also conspicuous at the scale of transmission electron microscopy (TEM) (see Maltman et al., this volume). TEM observations reveal the presence of zones of brecciation and a collapsed phyllosilicate framework within the shear surfaces discussed above. The breccia fragments appear to be composed of clasts that contain a fabric created during an earlier deformation event in the décollement zone, suggesting multiple episodes of deformation.

We also completed a CT scan of a sample from the décollement zone (Sample 131-808C-69R-2, 72-74 cm, in Table 1; Pl. 5, Fig. 2)
Table 2. Typical chemical profile from the vein material shown in Plate 3.

\begin{tabular}{llrrrrrr}
\hline $\begin{array}{l}\text { Element } \\
\text { and line }\end{array}$ & & K-ratio & $\begin{array}{c}\text { Weight } \\
\text { percent }\end{array}$ & $\begin{array}{c}\text { Precision } \\
2 \text { sigma }\end{array}$ & Formula & $\begin{array}{r}\text { Oxide } \\
\text { percent }\end{array}$ & $\begin{array}{c}\text { No. of cations } \\
\text { in formula }\end{array}$ \\
\hline $\mathrm{Si}$ & $\mathrm{KA}$ & 0.5749 & 31.11 & 0.08 & $\mathrm{SiO}_{2}$ & 66.55 & 9.2731 \\
$\mathrm{Ti}$ & $\mathrm{KA}$ & 0.0012 & 0.08 & 0 & $\mathrm{TiO}_{2}$ & 0.13 & 0.0137 \\
$\mathrm{Al}$ & $\mathrm{KA}$ & 0.1181 & 7.01 & 0.02 & $\mathrm{Al}_{2} \mathrm{O}_{3}$ & 13.24 & 2.1744 \\
$\mathrm{Fe}$ & $\mathrm{KA}$ & 0.0023 & 0.18 & 0.01 & $\mathrm{FeO}^{\mathrm{O}}$ & 0.23 & 0.0272 \\
$\mathrm{Mn}$ & $\mathrm{KA}$ & 0.0003 & 0.02 & 0 & $\mathrm{MnO}$ & 0.02 & 0.0028 \\
$\mathrm{Mg}$ & $\mathrm{KA}$ & 0.0001 & 0.01 & 0 & $\mathrm{MgO}$ & 0.02 & 0.0037 \\
$\mathrm{Ca}$ & $\mathrm{KA}$ & 0.0263 & 0.95 & 0 & $\mathrm{CaO}$ & 1.33 & 0.1984 \\
$\mathrm{Na}$ & $\mathrm{KA}$ & 0.2461 & 3.04 & 0.03 & $\mathrm{Na}_{2} \mathrm{O}$ & 4.1 & 1.1083 \\
$\mathrm{~K}$ & $\mathrm{KA}$ & 0.0641 & 0.88 & 0.01 & $\mathrm{~K}_{2} \mathrm{O}$ & 1.06 & 0.1886 \\
$\mathrm{P}$ & $\mathrm{KA}$ & 0.0097 & 0.25 & 0 & $\mathrm{P}_{2} \mathrm{O}_{3}$ & 0.58 & 0.0689 \\
$\mathrm{~S}$ & $\mathrm{KA}$ & 0.0041 & 0.14 & 0 & $\mathrm{SO}_{3}$ & 0.36 & 0.0373 \\
$\mathrm{Cl}$ & $\mathrm{KA}$ & 0.0016 & 0.07 & 0 & $\mathrm{Cl}^{2}$ & 0.07 & 0 \\
${ }^{\mathrm{O}}$ & & & 43.95 & & & & \\
Total & & & & & & 87.69 & 13.0965 \\
\hline
\end{tabular}

Note: The data were collected with an energy dispersion detector attached to a microprobe. The relatively high silica and aluminum contents suggest the presence of a feldspar or an intergrowth of quartz and feldspar (or zeolite).

${ }^{a} \mathrm{~K}$-ratio $=\mathrm{K}$-ratio $\times \mathrm{R}$ where $\mathrm{R}=$ reference(standard)/reference(sample).

${ }^{b}$ Number of cations calculated on basis of 23 oxygen atoms.

'Determined by stoichiometry.

and there are two significant results. First, the CT numbers and the corresponding attenuation coefficients are the highest measured, including the measurements from within the deformation zones at shallower levels. Apparently, the décollement contains some of the most dense sediments drilled at Site 808; this result is also consistent with the relatively high densities and low porosities measured on the Resolution. Second, although the sample analyzed was relatively small, the sample does not appear to contain discrete zones of deformation. Instead, the CT images show a more homogeneous, but relatively dense, internal structure. Presumably, the small slip surfaces observed in thin-sections (e.g., Pl. 4, Fig. 2) are simply not resolvable at the scale of the X-ray tomography. This is consistent with the theoretical resolution of the JACK-320 which is $1-2 \mathrm{~mm}$.

When taken together, the microscopic, TEM, and X-ray scanning data suggest a cyclic deformation sequence: displacement-brecciation-porosity collapse and compaction. We also infer that this cyclic deformation was associated with a changing permeability behavior as the sample progressively consolidated.

\section{EXPERIMENTAL DATA}

The ability of fluids to move through sediments is expressed numerically through the coefficient of hydraulic conductivity which, in part, is a function of permeability. In the kinds of sediments of relevance here, this ability will vary in different directions ("anisotropic permeability"), in particular between the horizontal and vertical (e.g., Taylor and Leonard, 1990). It can also be influenced by any deformational structures that are present (Arch and Maltman, 1991). In an active accretionary prism, it is conceivable that the permeabilities during deformation ("dynamic permeability") are significantly different from those in the materials at rest (static permeability). The difference has been little explored.

It has been suggested (e.g., Langseth et al., 1988) that laboratory permeability measurements of ODP core material from actively deforming prisms may be underestimating the in-situ values. It is important to gain at least some idea of the extent to which active deformation influences permeability. Downhole measurements of permeability, however, remain extremely elusive. In this section we report preliminary results from experiments on the interaction of deformation and permeability, and it is clear that the relationships are not straightforward.

\section{Method}

The experimental apparatus (at University College, Wales) was designed to measure the rate of fluid outflow from samples of ODP core and analog materials while the materials are at rest (static 


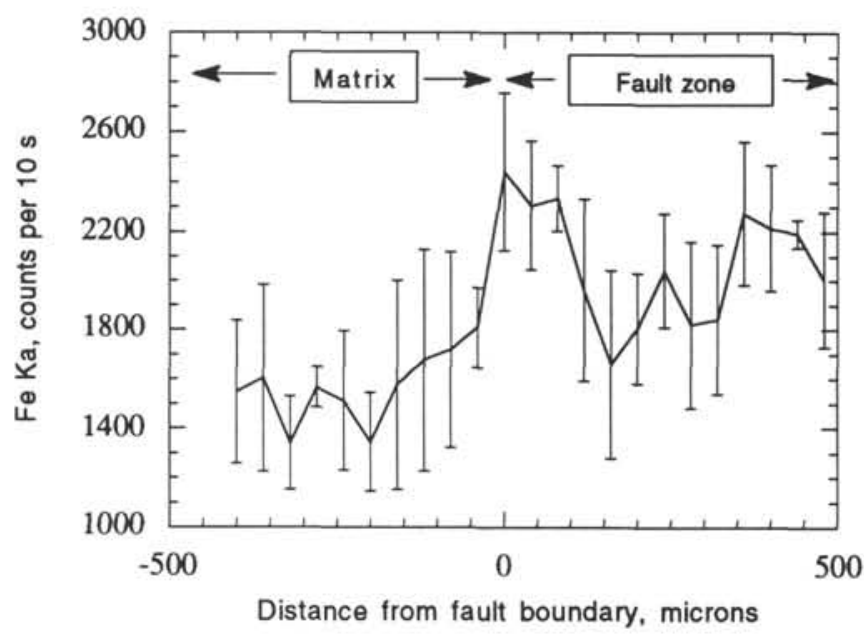

Figure 7. Microprobe transect across a fault zone similar to the one shown in Plate 5, Figure 2. The fault zone appears relatively dark in hand sample. The $\mathrm{y}$-axes shows the concentration of Fe in terms of the number of counts per second; a relatively poor polish and high porosity inhibited collecting quantitative data from this sample. The boundary between the fault zone and the wall rock is at the zero mark on the $\mathrm{x}$-axis. Note the increase in $\mathrm{Fe}$ at the boundary and the generally higher Fe concentration within the fault zone.

experiments) and during deformation (dynamic experiments). At present, it is not possible to monitor the fluid entering the specimen during the experiment. Consequently, we are not able to calculate whether there is a retention of fluid by dilation in the sample or an expulsion of fluids caused by porosity collapse and grain reorientation within the sample. The calculated permeabilities should therefore be considered apparent, especially for the dynamic experiments. The apparatus and method are briefly outlined below.

Cylindrical samples, $100 \mathrm{~mm}$ long $\times 54 \mathrm{~mm}$ diameter, are trimmed from whole-round ODP cores, or from analog sediments generated as described in Maltman (1987) and placed in a conventional triaxial cell. A confining pressure is maintained at a slightly higher value than the fluid pressures in the sample, in order to prevent flow of water between the protective rubber sleeve and the specimen, which would give an artificially high permeability value. In the tests reported here, no attempt was made to simulate the in-situ confining and pore pressures or fluid pressure gradients of the prism, partly because the fluid values, in particular, are so little known.

Distilled water (which limits corrosion of the apparatus) at a constant pressure was fed to the upstream end of the sample, and the amount of downstream effluent precisely measured. With careful monitoring by a differential pressure transducer of the hydraulic head across the specimen, all the parameters required to calculate the static permeability are available, assuming Darcian flow. Permeability measurements can also be made while deforming the sample with constant head via deviatoric stress in a normal triaxial cell.

The amount of effluent was monitored by constantly weighing it on an electronic balance and converting the value to a volume. The apparatus presently measures outflow from the specimen to $10^{-4} \mathrm{~cm}^{3}$. We used this technique because of the great sensitivity and its facility for constant monitoring through a computer. Because the specimens were sealed immediately after sampling, stored in a humidity cabinet, and only unsealed at the time of the test, they were likely to be fully saturated. The pipework and mode of pressure application within the apparatus is designed to exclude any air bubbles in the system. Evaporation from the downstream receptacle is known to be insignificant. This conceptually simple system produces reproducible results and is highly sensitive to changes in flow rate during deformation.

A program prompts the computer to read the various pressure and strain transducers in the system, and the electronic balance at prede- termined intervals, normally governed by the strain rate, in order to calculate permeability. The permeability is normally plotted against time for a static test, to check the consistency of the value, and against strain for a dynamic test, to highlight deformation-flow interactions.

\section{RESULTS}

\section{Static Permeability}

The natural prism samples analyzed by the above method are from 196 mbsf (131-808G-8X-3) and 347 mbsf (131-808C-6R-1). When unsealed, the two specimens differed markedly in consistency: the former was soft and weak, bulging when standing unsupported, while the latter was stronger and rigid. The formal sample was handled quickly and carefully to minimize disturbance of the fabric. The contrast in the samples is also evident in their permeabilities; the shallower having a value of $3 \times 10^{-16} \mathrm{~m}^{2}$, while the more deeply buried sample gave a value of $3 \times 10^{-18} \mathrm{~m}^{2}$, a difference of $10^{2} \mathrm{~m}^{2}$ (Figs. 8A and 9A).

The two permeability values presumably reflect the differing degrees of consolidation and hence packing of the sediment particles in the two specimens, but, nevertheless, the deeper sample shows a permeability much lower than the general trend of the compiled data of Elliot et al. (this volume). The explanation may lie in the internal fabric of this sample. The zone where this sample is from (near the frontal thrust) is especially rich in deformation bands (Taira, Hill, Firth, et al., 1991, fig. 59) and dark traces of the bands were visible on the sample sides. The bands also produced small (millimeter scale) steps at the ends of the core. The bands from this sample have not yet been analyzed microscopically, but they appear to be similar to the kink-like bands described above and in Maltman et al. (this volume). The bands have apparently decreased the permeability of this sample through a combination of porosity reduction and/or fabric anisotropy.

A third sample from about these same depths also shows anomalously low permeabilities. This sample (131-808C-21R-5) is from $497 \mathrm{mbsf}$ and was analyzed at University College, London, through the kind courtesy of Dr. Mervyn Jones. These tests were carried out at estimated ambient burial pressures, in both the vertical and horizontal directions. The permeability in each direction was assessed at two different effective confining pressures. Further details of the experimental conditions are given in Figure 10.

The results show surprisingly low values of permeability. All values fall within the range $10^{-18}$ to $10^{-20} \mathrm{~m}^{2}$, approximately three orders of magnitude lower than a linear trend that might be inferred from the data compiled by Elliot et al. (This volume). The other curiosity arises from the relative magnitudes of the vertical and horizontal permeabilities. The latter would be expected to give the greater values, through the reduced path tortuosity resulting from the consolidation fabric, but the results show the reverse. The horizontal permeability is lower than the vertical by $30 \%$. Care was taken to avoid disturbance of the sample during its preparation; disturbance of the primary fabric is therefore not considered to have been a factor (M. Jones, pers. comm., 1991). The explanation may again lie with the presence of deformation structures. They are plentiful in the cores from which this sample was taken, but as yet the relevant microstructural analysis of this sample has not been conducted.

\section{Dynamic Permeability}

The permeability and stress-strain behavior of the dynamic permeability experiments for one ODP sample and two analog materials are shown in Figures 8,11, and 12. Although the general form of the curves is clear, scatter due to electronic noise may mask some subtleties of the specimen's mechanical response. The results plainly show, however, that active deformation modifies fluid flow, but the effect is not a simple one. The stress-strain curves indicate variable styles of deformation, and as strain progresses, increases and decreases in permeability are observed. Specific aspects of this fluid flow 
A

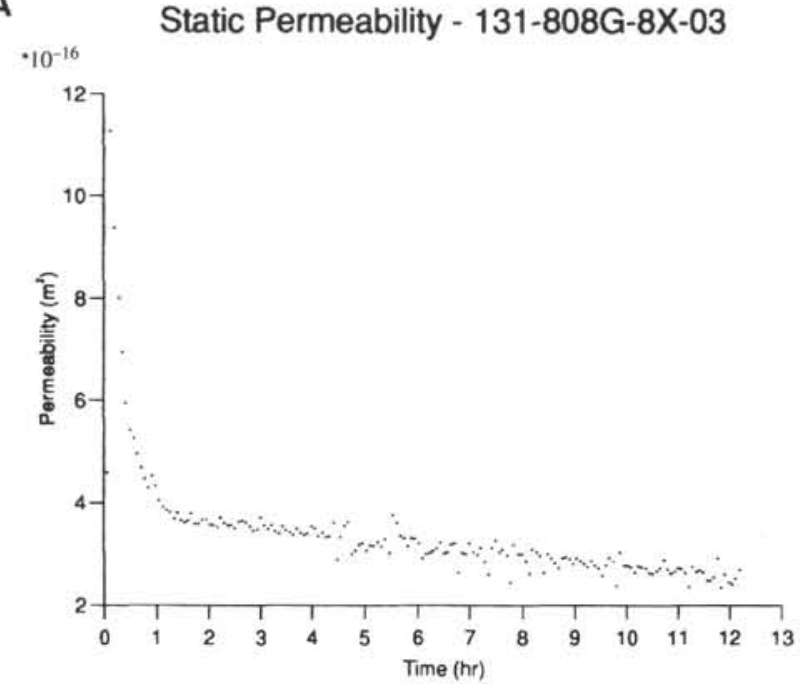

B

$\cdot 10^{-16}$



Figure 8. A. Static permeability (top) of Section 131-808G-8X-3, a weak, highly porous silty clay from $196 \mathrm{mbsf}$ at Site 808 , Nankai prism, $3 \times 10^{-16} \mathrm{~m}^{2}$. B. Dynamic permeability (bottom), measured as explained in the text, is lower, falling rapidly to about $1 \times 10^{-16} \mathrm{~m}^{2}$, with at least two perturbations during increasing strain.

behavior in both the natural prism material and the laboratory generated analogs are presented below.

The sample from 196 mbsf at Nankai (131-808G-8X-3) was deformed at a strain rate of $1.51 \times 10^{-4} \mathrm{~s}^{-1}$ and shows an overall decrease in permeability as strain increases, from $2.3 \times 10^{-16} \mathrm{~m}^{2}$ to $1.25 \times 10^{-16} \mu^{2}$. The decrease is initially rapid, then occurs at a reduced rate beyond $5 \%$ strain (Fig. 8). A small upward step in the permeability curve occurs at $10 \%$ strain, corresponding to a more rapid change in gradient of the stress-strain curve. There is, however, no marked failure point. Macroscopically, this specimen deformed by barreling, and later CT-scanning confirmed that no failure planes had developed.

At approximately $18 \%$ strain, an abrupt increase in permeability occurs. It seems unlikely that this effect is due to noise or some other artifact, for, although the permeability increases suddenly, the decrease is gradual, occurring over a $3 \%$ increase in strain. This means numerous computer readings are represented, rather than a single anomalous value, and that it is not a fluctuation about a mean value, as occurs in the stress-strain curves. While it is possible that a very small fluctua- tion in the stress-strain curve at that point is largely hidden within the noise, it appears that there is no corresponding marked change in stress-strain behavior. It does seem, therefore, that this represents a real variation in permeability.

Similar small changes are seen in the dynamic permeability behavior of the sand/kaolinite specimen (Fig. 11) although, in this sample, the permeability generally increases with additional deformation. At $9 \%$ strain, a break in the permeability curve, with a small increase followed by a decrease back to the former permeability value, corresponds to a stress drop with increasing strain. The failure point is more marked than in the natural Nankai sample. At approximately $21 \%$ strain, there is an abrupt jump, less marked than in the Nankai sample, but of similar shape, but with no apparent deflection of the stress-strain curve.

The abrupt, asymmetrical kick in permeability remains to be explained. The observed fluctuations at lower strain correlate with changes in the stress-strain rate, and apparently correspond to a yield point in the material. This is known to be a point in which the generation of deformation structures is prolific (Maltman, 1987), and it may be that dilation (i.e., local volume increase) associated with particle reorientation into shear-zone-like structures is accompanied by a transient increase in permeability. It is also possible that the collapse and reorientation particles expelled fluid (i.e., volume decrease), leading to an apparent permeability increase. Both hypotheses are also consistent with observations from the deformation structures at Nankai. At the present time, the volume changes occurring at these stress-strain increments are not known with sufficient accuracy to resolve between these two possibilities. Both interpretations imply, however, that production of the deformation structures is affecting waterloss, and that the detailed hydrology of Nankai will differ from a prism that lacks abundant deformation features.

Triaxial testing of the ball clay specimen showed a particular complex permeability and stress-strain pattern (Fig. 12). There is an overall strain-induced decrease from $3 \times 10^{-17} \mathrm{~m}^{2}$ to $2.0 \times 10^{-17} \mathrm{~m}^{2}$, with steps of increased permeability at $6 \%-10 \%$ strain and $15 \%-19 \%$ strain. These intervals have corresponding fluctuations in post-failure regions of the stress-strain curve. The permeability appears to fall during increments of strain-hardening, and rise with strain-softening. The explanation may again involve processes of dilation and/or volume loss, but a detailed understanding awaits the microstructural analysis of the specimens.

\section{Discussion of Experimental Results}

The ability of a sediment to transfer water is clearly modified during active deformation. Permeability may change by as much as $50 \%$. Weak, porous materials, such as that from 196 mbsf at Nankai, appear to undergo a permeability decrease with increasing strain, perhaps because the deformation is "tightening up" the grain packing. This specimen failed by pervasive grain slippage rather than the development of discrete deformation bands. Some stronger materials, as yet only tested as laboratory analogs, show a permeability increase with strain as well as an increase in permeability with strain softening. In detail, however, the behavior is complex, with transient permeability increases at failure, and at higher strain values. The former may be associated with dilatancy or fluid expulsion during grain reorientation, but the latter remains an unexplained phenomenon.

Deformation not only influences permeability in these active ways, but the resulting structures can also affect the flow paths. If the deformation structures act as conduits to fluid flow, this may lead to concentrated diagenesis within the structures transforming the structures into fluid flow barriers. Two Nankai samples are known to contain such deformation structures and both show unusually low permeabilities. One of the samples, from 497 mbsf, also shows an anomalous permeability anisotropy, with values lower in the horizontal direction than those in the vertical. Permeability anisotropy, therefore, may govern the ability of this Nankai sediments to transfer fluid. 
Static Permeability - 131-808C-6R-01

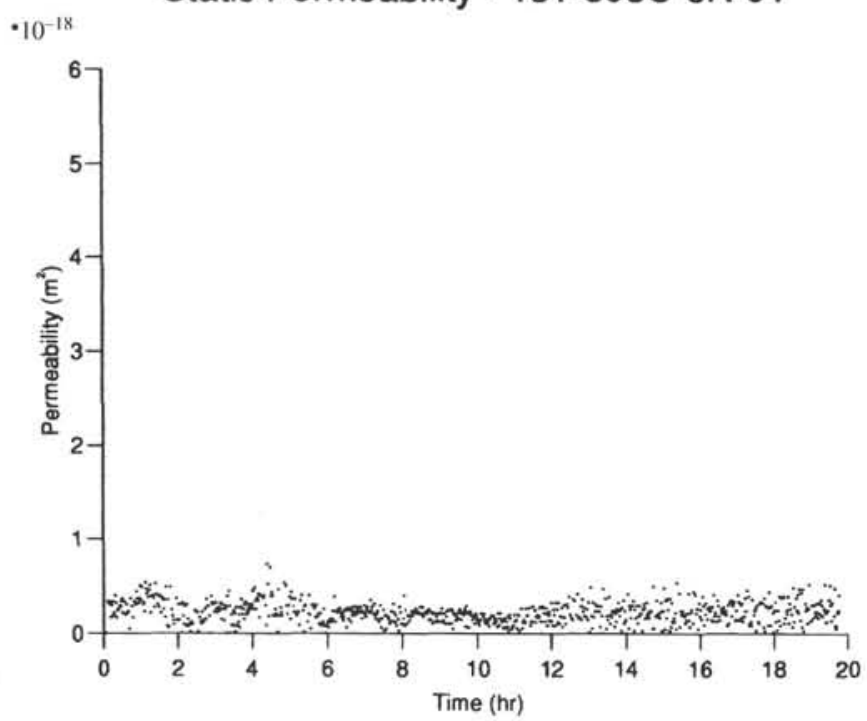

Figure 9. Static permeability of Section 131-808C-6R-1, a silty clay from 347 mbsf, just within the frontal thrust zone of the Nankai prism, $3 \times 10^{-18} \mathrm{~m}^{2}$.

\section{SUMMARY AND DISCUSSION}

In the previous paragraphs we have emphasized three fundamental aspects of the relation between deformation and fluid flow in the Nankai accretionary prism. First, the sediments above the décollement are tectonically overconsolidated. Overconsolidation is indicated by an anomalous porosity vs. depth function (Taira, Hill, Firth, et al., 1991; Bruckmann et al., this volume) and by magnetic susceptibility and velocity anisotropies subparallel to bedding. Overconsolidation appears to have occurred relatively early in the history of accretion because the magnetic susceptibility fabrics are deformed by the frontal thrust. We infer that overconsolidation was accommodated by pervasive, intergranular dewatering although channelized flow may have occurred locally.

Second, detailed thin-section and computed tomography studies indicate that essentially all of the deformation structures above the décollement record various stages of densification. Densification has apparently occurred through porosity collapse and phyllosilicate reorientation and alignment. That is, development of the structures appears to have resulted in an increase in density and a decrease in porosity relative to the surrounding sediments. One important exception occurs at about $800 \mathrm{mbsf}$ where thin-section scale veins (zeolite?) and hydrobreccia have been recognized. We infer that this zone represents a now inactive proto-décollement that formed at the base of the relatively ash-rich upper Shikoku Basin sediments. Although the absence of evidence for concentrated fluid flow (e.g., veins, dikes, and dewatering pipes) throughout the rest of the prism suggests that concentrated fluid flow is a subordinate process, it can not be eliminated. Our working hypothesis, however, is that the mesoscopic scale deformation structures accommodated only limited fluid flow from locally derived reservoirs (i.e., the pore fluids in the sediments near the structure).

Dynamic and static permeability studies of the Nankai sediments are also consistent with this hypothesis although some ambiguities remain in interpreting the experimental results. These studies show three main conclusions: (1) the deformation structures appear to be barriers to fluid flow, (2) there is a general decrease in permeability as deformation occurs with the exception of (3) pulses of transient permeability increases as the sediment fails and at high strain values. The pulses of increased permeability may reflect either a transient episode of dilation followed by pore collapse and a decrease in perme- ability or they may represent a single, permanent episode of porosity collapse and dewatering with an apparent increase in permeability.

Finally, the décollement zone contains an unusual phyllosilicate fabric and TEM studies indicate multiple episodes of fabric collapse, brecciation, and dewatering (Maltman et al., this volume). The absence of well developed phyllosilicate fabrics in the décollement is especially surprising considering the much higher strain along this zone than along most of the deformation zones above the décollement. To reconcile these fundamental differences, and to attempt to integrate many of the above observations, we propose the following deformation scenarios for sediments above and within the décollement zone.

Sediments above the décollement preserve an initial bedding/compaction grain fabric that is modified by bedding-parallel compression during the early stages of accretion (Owens, this volume). This early stage of compression is inferred to have been accommodated by volume loss and grain realignment, and, in the interval near the frontal thrust, by the formation of kink-like deformation bands (Byrne et al., this volume). As accretion and deformation continued, small fault zones propagated throughout the accreting sediments. Because these structures are presently characterized by a decreased density and porosity, we infer that as the fault formed, a transient pulse of increased permeability allowed dewatering to occur. Whether this permeability pulse was accommodated by a dilatory and/or compactive strain wave, or both, can not be resolved. In general, however, the deformation structures above the décollement appear to record only a single pulse of dewatering and consolidation.

In contrast, the dewatering and deformation histories of the sediments within the décollement appear to be more protracted and less systematic. Samples from the décollement are distinctively "mottled" and display a domainal texture at both microscopic and submicroscopic scales (e.g., Pl. 4). The shear surfaces are typically much thinner and more irregular and discontinuous than similar surfaces from above the décollement. TEM observations also reveal the presence of zones of brecciation and a collapsed phyllosilicate framework between individual shear surfaces. These observations suggest a cyclic history of shear induced brecciation (and probably dilation) followed, at least locally, by pore collapse and phyllosilicate reorientation (Fig. 13). Although, in general, this history is similar to that inferred for the deformation structures above the décollement, the décollement history is different in two important aspects. First, the décollement samples appear to record cyclic events of brecciation and fabric collapse. Second, the zones of fabric collapse are much narrower and they are more disseminated throughout the zone. Both of these differences could account for the greater density of the décollement samples.

We suspect that these fundamental differences reflect the different structural positions and different fluid histories of the two suites of rocks. Specifically, we propose that the décollement zone has been repeatedly deformed as overpressured fluids leak upward from the underlying lower Shikoku basin sediments (Fig. 2). Taira, Hill, Firth, et al. (1991) argued that the underthrusting sediments are relatively water-rich and overpressured, based on the much higher porosities of these sediments. This interpretation is also supported by the reversed seismic polarity across the décollement (Moore et al., 1990). We therefore consider the décollement to be a zone of relatively low shear stress that fails episodically as pulses of overpressuring migrate upward from the underthrust sediments. It is important to emphasize that, if the fluid pathways remain generally connected between the footwall and the décollement, fluid migration is not required between the underthrust sediments and the décollement, only the pulse of overpressuring needs to migrate to cause failure. In fact, the relatively low porosities within the décollement indicate fluids have generally moved out of this zone. Local hydraulic gradients may have driven these fluids up- or downsection.

In total, we envision the Nankai accretionary prism as being composed of three structural/hydrologic regimes. The regime above 


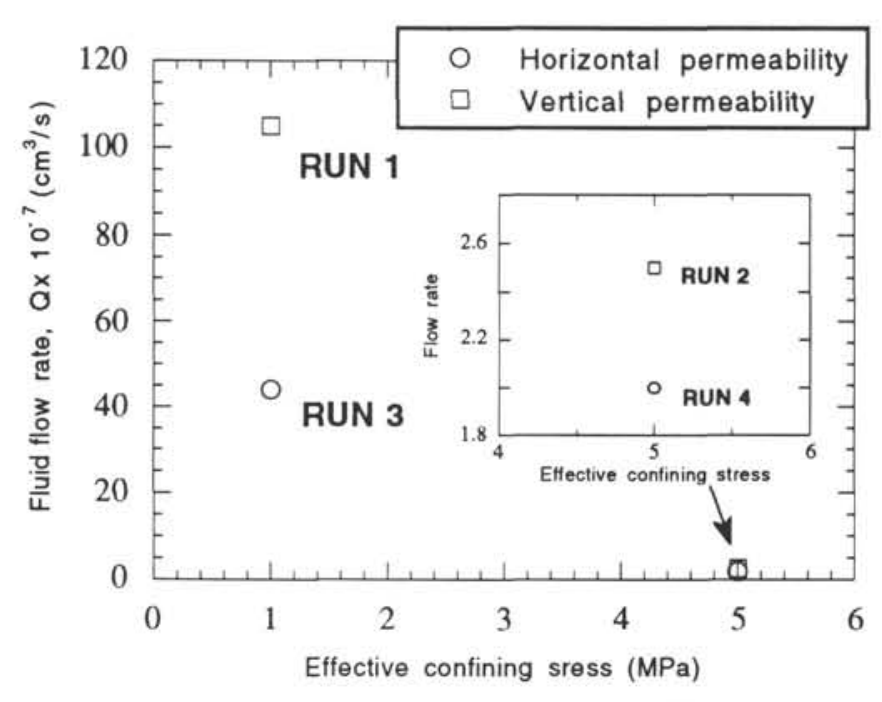

Figure 10. Results of four (two vertical and two horizontal) static permeabilities of specimen from Section 131-808C-21R-5, a silty clay from $497 \mathrm{mbsf}$ in the Nankai prism. Run 1: at a total confining pressure of $20.99 \mathrm{MPa}$, bottom pore pressure of $20.00 \mathrm{MPa}$, and top pore pressure of $19.51 \mathrm{MPa}$, corresponds to a permeability of $1.3 \times 10^{-18} \mathrm{~m}^{2}$. Run 2: at a total confining pressure of $25.01 \mathrm{MPa}$, bottom pore pressure $20.00 \mathrm{MPa}$, and top pore pressure of $19.43 \mathrm{MPa}$, corresponds to a permeability of $1.8 \times 10^{-20} \mathrm{~m}^{2}$. Run 3 : at a total confining pressure of $21.1 \mathrm{MPa}$, bottom pore pressure of $20.09 \mathrm{MPa}$, and top pore pressure of 19.58 $\mathrm{MPa}$, corresponds to a permeability of $3.2 \times \mathrm{s} 10^{-19} \mathrm{~m}^{2}$. Run 4 : at a total confining pressure of $25.0 \mathrm{MPa}$, bottom pore pressure of $20.00 \mathrm{MPa}$ and top pore pressure of $19.41 \mathrm{MPa}$, corresponds to a permeability of $1.3 \times 10^{-20} \mathrm{~m}^{2}$. These data were kindly provided by Dr. Mervyn Jones, University College, London.

the décollement is characterized by sediments that are progressively dewatered through the development of both penetrative fabrics and a pervasive, but apparently poorly interconnected, set of core-scale deformation structures (i.e., faults and kink-like structures). In this regime individual structures probably strain-harden (e.g., Moore and Byrne, 1987), and shortening is accommodated by the formation of new structures elsewhere in the prism, resulting in a structure distribution of about five structures/meter (Taira, Hill, Firth, et al., 1991). The décollement is characterized by a much higher density of structures/meter (probably an order of magnitude higher) and we consider this to be a regime of low stress but frequent failure. Individual deformation zones also probably strain-harden in this regime but, because the entire regime is at least episodically overpressured, deviatoric stresses are low and displacements are small on individual faults. Moreover, potential failure surfaces are as pervasive as any fluid phase that is present. Hydrologically the décollement retards the vertical flow of fluids and enhances the potential for overpressuring in the footwall because episodic failure progressively decreases the porosity, and thus probably also the hydraulic conductivity. Finally, the footwall regime contains very few tectonic structures and is structurally isolated from the subhorizontal stresses related to plate convergence. This regime provides an important component to the tectonics of the Nankai prism, however, because it supplies the overpressured fluids that cause failure of the décollement at relatively low shear stresses.

\section{ACKNOWLEDGMENTS}

We thank the National Science Foundation (U.S.A.) and Natural Environment Research Council (United Kingdom) for supporting Leg 131 and several parts of the post-cruise research. We thank our shipboard colleagues for assistance in collecting some of the data, especially W.H. Owens and R. Lu for discussions about the use of remanent magnetization. A careful study by Dan Orange is also greatly appreciated.

\section{REFERENCES}

Anderson, S.H., Gantzer, C.J., Boone, J.M., and Tully, R.J., 1988. Rapid nondestructive bulk density and soil-water content determination by computed tomography. Soil Sci. Soc. Am. J., 52:35-40.

Anderson, T., 1968. The geometry of a natural orthorhombic system of kink bands. Pap.-Geol. Surv. Can., 68-52:200-220.

Arch, J., and Maltman, A., 1990. Anisotropic permeability and tortuosity in deformed wet sediments. J. Geophys. Res., 9035-9045.

Bamford, D., and Nunn, K., 1979. In situ seismic measurements of crack anisotropy in the carboniferous limestone of northwest England. Geophys. Prospect., 27:322-338.

Biju-Duval, B., Moore, J.C., et al., 1984. Proc. ODP, Sci. Results, 78: College Station, TX (Ocean Drilling Program).

Carson, B., and Berglund, P., 1986. Sediment deformation and dewatering under horizontal compression: experimental results. In Moore, J.C. (Ed.), Structural Fabrics in Deep Sea Drilling Project Cores from Forearcs. Geol. Soc. Am., 117-133.

Crestana, S., Mascarenhas, S., and Pozzi-Mucelli, R.S., 1985. Static and dynamic three-dimensional studies of water in soil using computed tomographic scanning. Soil. Sci., 140:326-332.

Graham, J.W., 1966. Significance of magnetic anisotropy in Appalachian sedimentary rocks. In Steinhard, J., and Smith, T. (Eds.), The Earth Beneath the Continents. Am. Geophys. Union, Geophys. Monogr., 10:627-648.

Langseth, M.G., Westbrook, G.K., and Hobart, M.A., 1988. Geophysical survey of a mud volcano seaward of the Barbados Ridge accretionary complex. J. Geophys. Res., 93:1049-1061.

Karig, D.E., 1986. Physical properties and mechanical state of accreted sediments in the Nankai Trough, Southwest Japan Arc. In Moore, J.C. (Ed.), Structural Fabrics in Deep Sea Drilling Project Cores from Forearcs. Mem.-Geol. Soc. Am., 117-133.

Karig, D.E., and Lundberg, N., 1990. Deformation bands from the toe of the Nankai accretionary prism. J. Geophys. Res., 95:9099-9109.

Knipe, R., Agar, S., and Prior, D., 1991. The microstructural evolution of fluid flow paths in semi-lithified sediments from subduction complexes. In Tarney, J., Pickering, K., Knipe, R., and Dewey, J. (Eds.), The Behaviour and Influence of Fluids in Subduction Zones. Proc. R. Soc. London, Discussion Meeting, 35-47.

Maltman, A., 1987. Shear zones in argillaceous sediments-an experimental study. In Jones, M.E., and Preston, R.M., Deformation of Sediments and Sedimentary Rocks. Geol. Soc. Am. Spec. Publ., 29:77-87.

, 1988. The importance of shear zones in naturally deformed wet sediments. Tectonophysics, 145:163-175.

Maltman, A., Byrne, T., Karig, D., Lallemant, S., and the Leg 131 Scientific Party, 1991. Structural geological evidence from ODP 131 regarding fluid flow in the Nankai Prism, Japan. Earth Planet. Sci. Lett., 109:463-468.

Moore, G.F., Shipley, T.H., Stoffa, P.L., Karig, D.E., Taira, A., Kuramoto, S., Tokuyama, H., and Suyehiro, K., 1990. Structure of the Nankai Trough accretionary zone from multichannel seismic reflection data. J. Geophys. Res., 95:8753-8765.

Moore, J.C., and Byrne, T., 1987. Thickening of fault zones: a mechanism of melange formation in accreting sediments. Geology, 15:1040-1043.

Moore, J.C., Mascle, A., Taylor, E., Andreieff, P., Alvarez, F., Barnes, R., Beck, C., Behrmann, J., Blanc, G., Brown, K., Clark, M., Dolan, J., Fisher, A., Gieskes, J., Hounslow, M., McLellan, P., Moran, K., Ogawa, Y., Sakai, T., Schoonmaker, J., Vrolijk, P., Wilkens, R., and Williams, C., 1988. Tectonics and hydrogeology of the northern Barbados Ridge: results from Ocean Drilling Program Leg 110. Geol. Soc. Am. Bull., 100:1578-593.

Petrovic, A.M., Siebert, J.E., and Rieke, P.E., 1982. Soil bulk density analysis in three dimensions by computed tomographic scanning. Soil. Sci. Soc. Am. J., 46:445-450.

Screaton, E.J., Wuthrich, D.R., and Dreiss, S.J., 1991. Permeabilities, fluid pressures, and flow rates in the Barbados Ridge complex. J. Geophys. Res., 95:8997-9007.

Suppe, J., 1985. Principles of Structural Geology: New Jersey (Prentice-Hall).

Taira, A., Hill, I., and Firth, J.V., 1991. Proc. ODP, Init. Repts., 131: College Station, TX (Ocean Drilling Program). 
Taira, A., and Niitsuma, H., 1985. Turbidite sedimentation in the Nankai Trough as interpreted from magnetic fabric, grain size and detrital modal analyses. In Kagami, H., Karig, D.E., Coulbourn, W.T., et al., Init. Repts. DSDP, 87: Washington (U.S. Govt. Printing Office), 611-632.

Taylor, E., and Leonard, J.N., 1990. Sediment consolidation and permeability at the Barbados forearc. In Moore, J.C., Mascle, A., et al., Proc. ODP, Sci. Results, 110: College Station, TX (Ocean Drilling Program), 289-308.
Wanner, G.S., Nieber, J.L., Moore, I.D., and Geise, R.A., 1989. Characterizing macropores in soil by computed tomography. Soil Sci. Soc. Am. J., 53:653-660.

Date of initial receipt: 11 October 1991 Date of acceptance: 11 September 1992 Ms 131SR-107

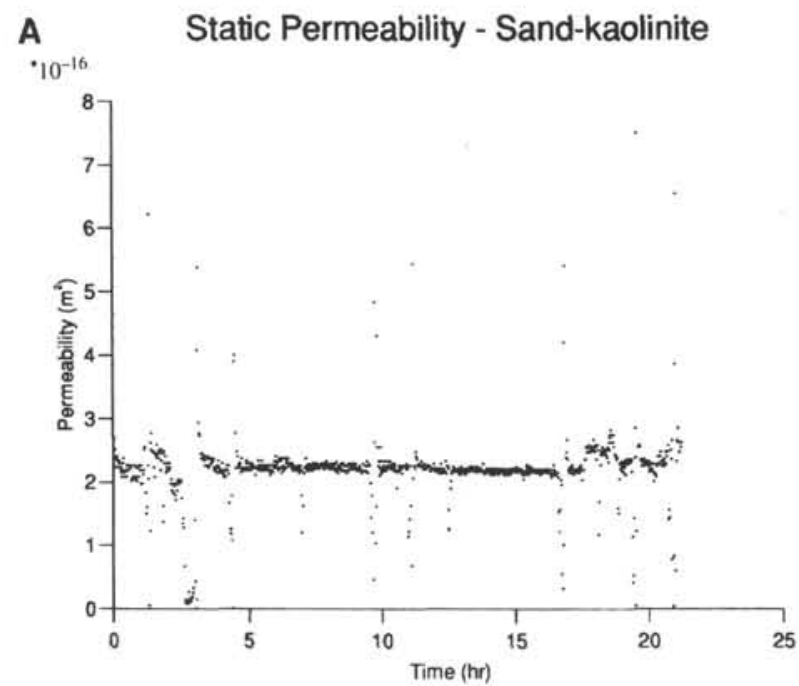

B Dynamic Permeability - Sand-kaolinite

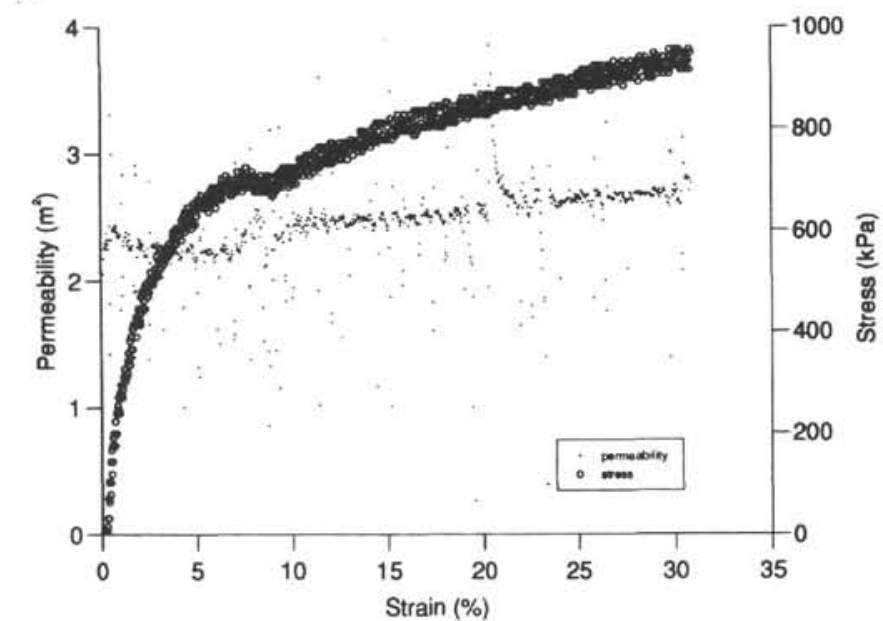

Figure 11. Static dynamic permeability of sand-kaolinite mixture consolidated to be analogous to Nankai sediments. A. Static permeability results show a constant permeability of $2 \times 10^{-16} \mathrm{~m}^{2}$. B. Dynamic permeability shows an increase with progressive strain, showing at least two perturbations. 
A

$$
\cdot 10^{-17}
$$

Static Permeability - Ball-clay

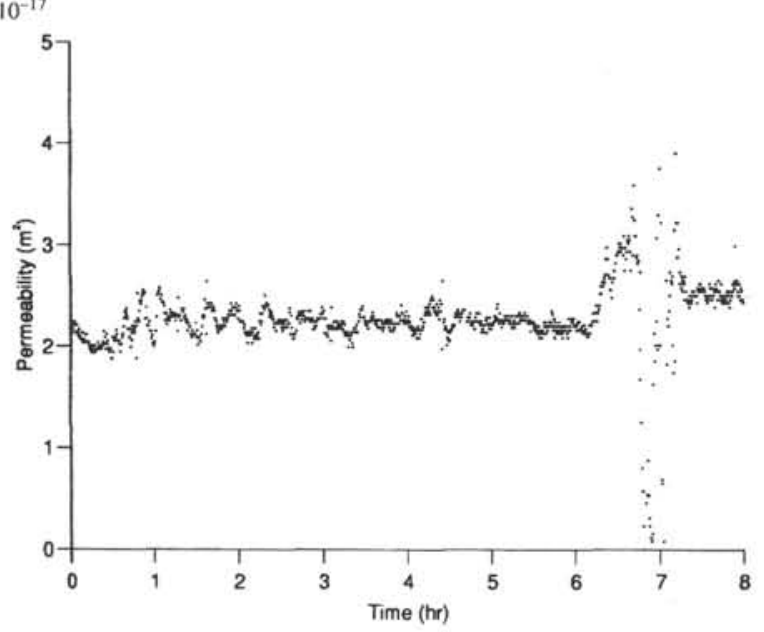

\section{B}

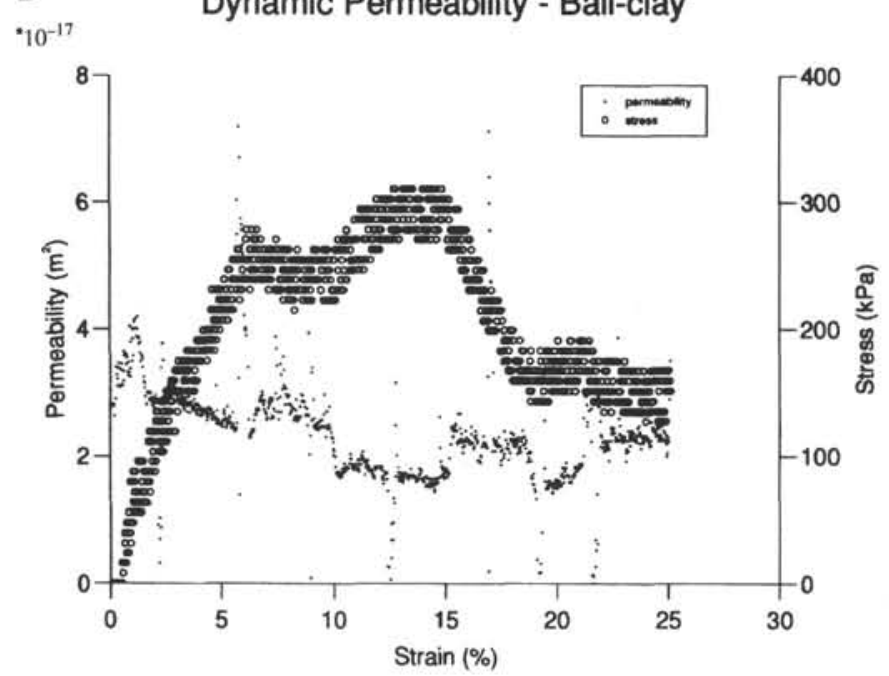



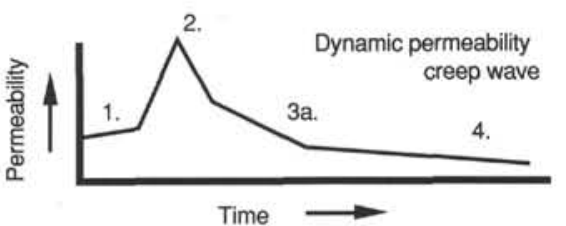

Figure 13. Interpretation of the cyclic and progressive development of scaly fabrics in the décollement zone. Shaded areas with thick lines are zones of locally reoriented phyllosilicates. Rapid and protracted dewatering paths are discussed in Knipe et al. (1991). Only the rapid dewatering path is shown in the permeability-time curve to emphasize the progressive consolidation of the sediments. We have inferred that recycling of the sediment through multiple deformation/compaction events is driven by pulses of fluid overpressures. Also, each deformation/compaction event probably progressively consolidates the sediments, resulting in anomalously low porosities and hydraulic conductivities.

Figure 12. Static permeability and dynamic permeability of ball clay consolidated to be analogous with sediments in the Nankai prism. A. Static permeability results are generally constant at about $2.3 \times 10^{-17} \mathrm{~m}^{2}$, although there is an anomalous jump after about $6.5 \mathrm{hr}$. B. Dynamic permeability results which show a more complex relation with strain. Note the two pulses of increased "apparent" permeability with pulses of strain softening. See text for discussion. 

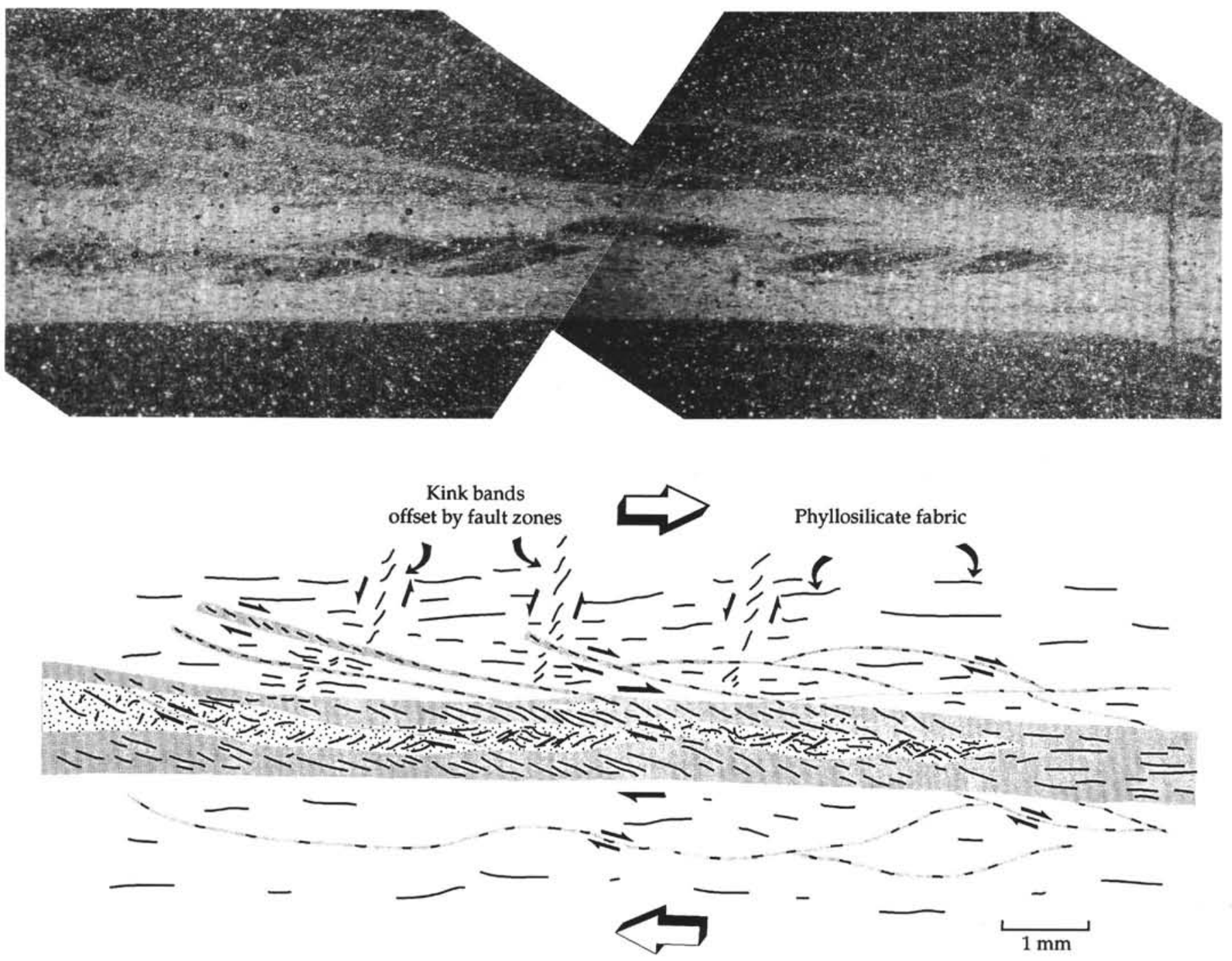

Plate 1. Photograph mosaic and sketch of a typical fault from the interval of the frontal thrust. Note particularly the well developed phyllosilicate fabric within the fault zone and the presence of small "pods" or lenses of disorientated (relative to the other fabrics in the zone) phyllosilicates. 


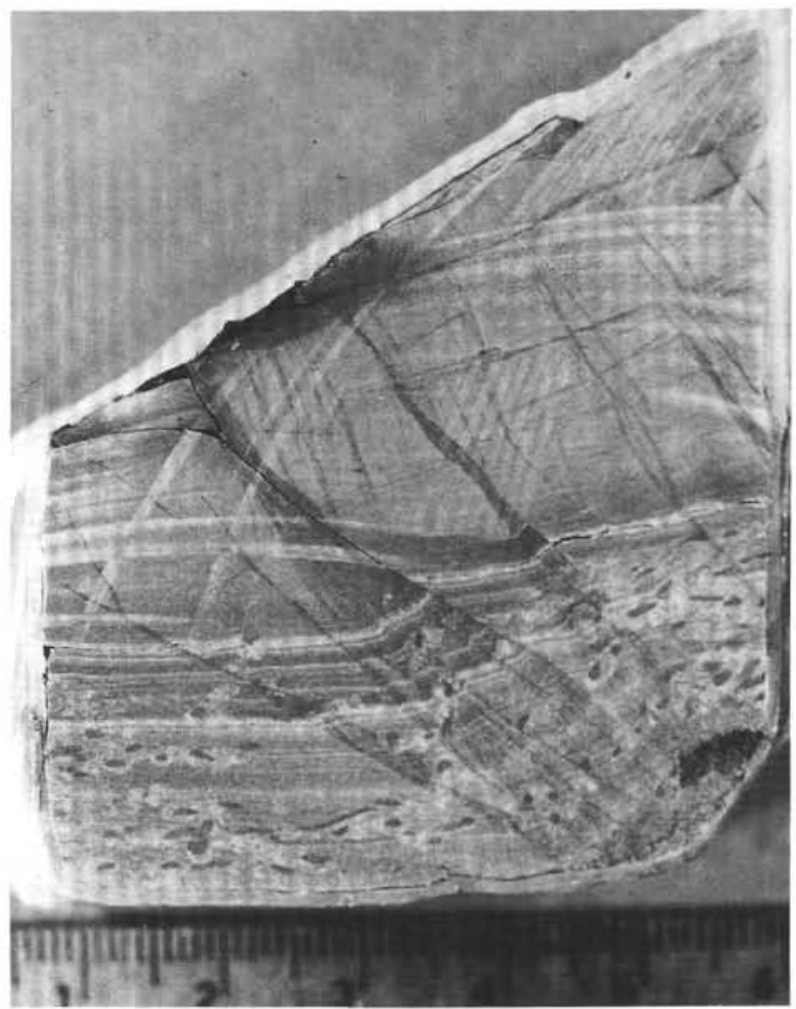

1

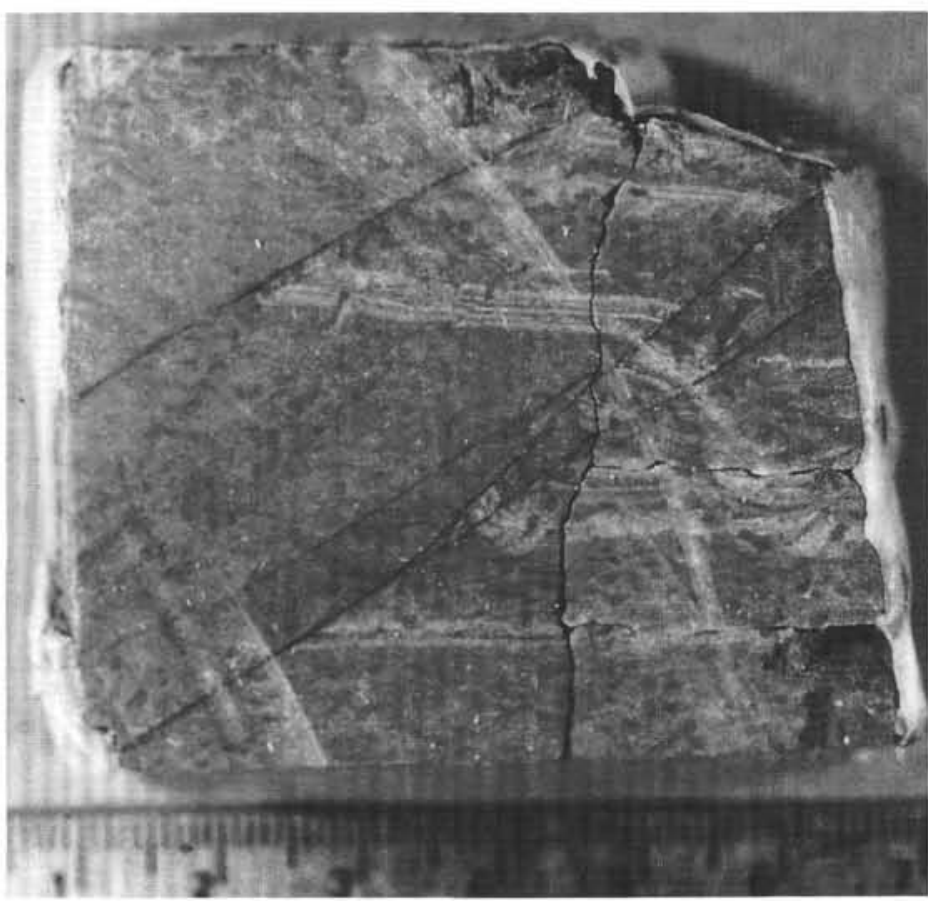

3

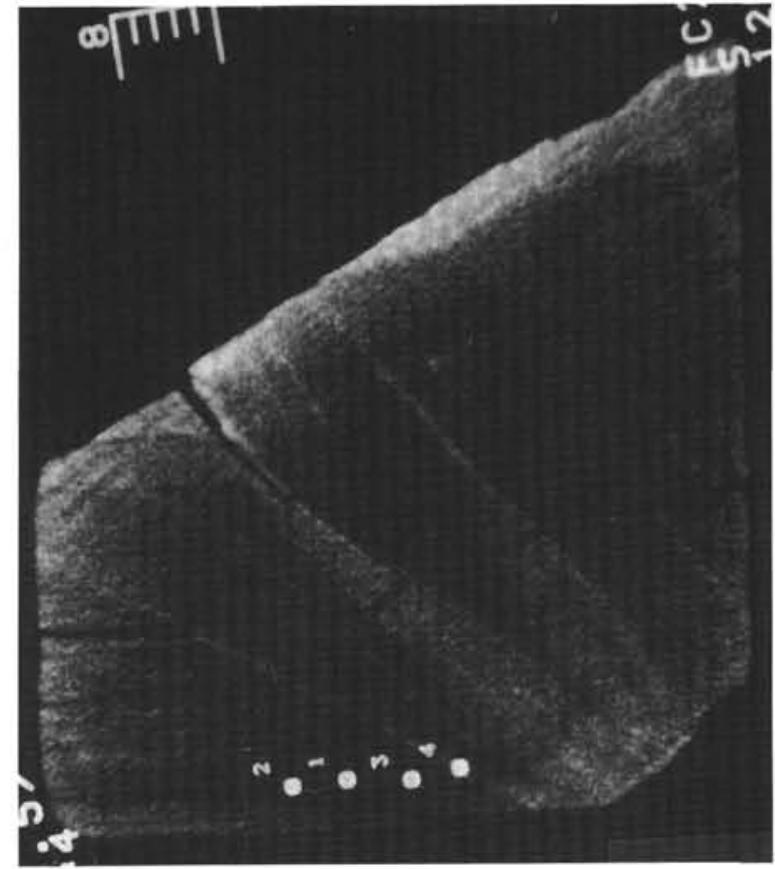

2

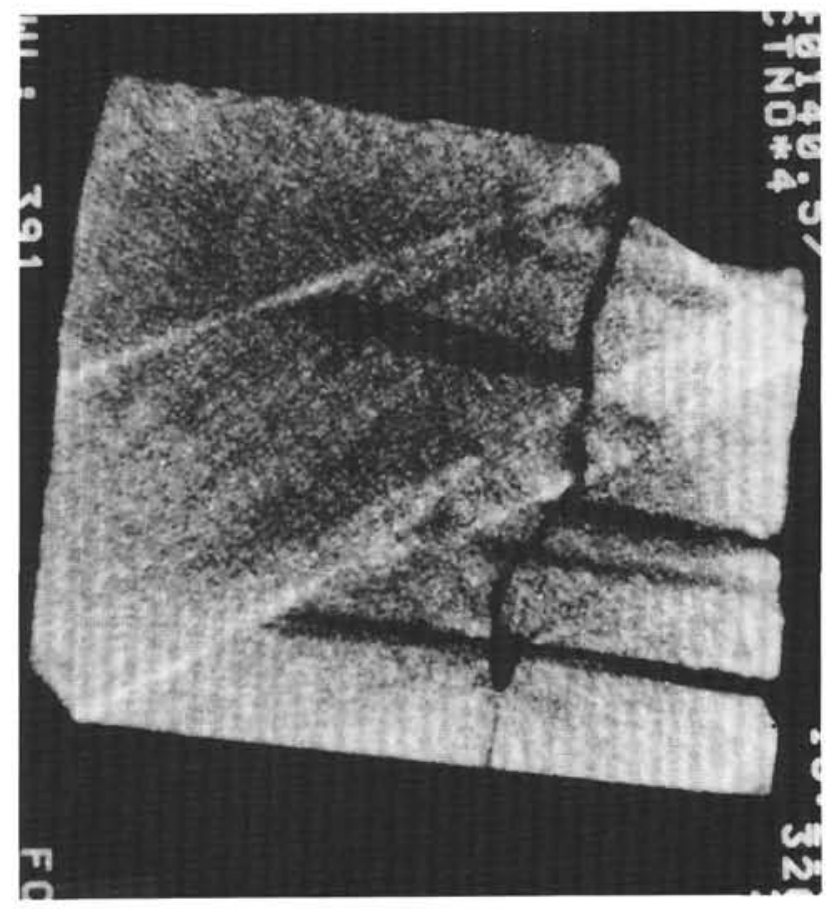

4

Plate 2. Photographs and CT scans of deformation structures from Site 808. 1. Core-scale photograph of kink-like bands. 2. A CT scan of the same sample. 3. Core-scale photograph of several small thrust faults 4. CT scan of the same sample. Note the close correlation between the bright areas in the CT scans and the individual faults and bands. The bright areas show zones of relatively high density which we infer to reflect a decrease in porosity. In Figures 3 and 4 the fault zones appear to be more dense than the silty matrix that forms most of the sample. Similarly, the matrix appears to be more dense than the thin layers of sand that define bedding and are subhorizontal (i.e., parallel to the ruler). Locally, some of the fault zones have slightly higher concentrations of Fe, which also may explain the higher CT values and densities in these samples. The amount of offset of the lower fault zone is about $3 \mathrm{~cm}$. Both photographs show surfaces that are parallel to the movement direction of the kink-like zone. 


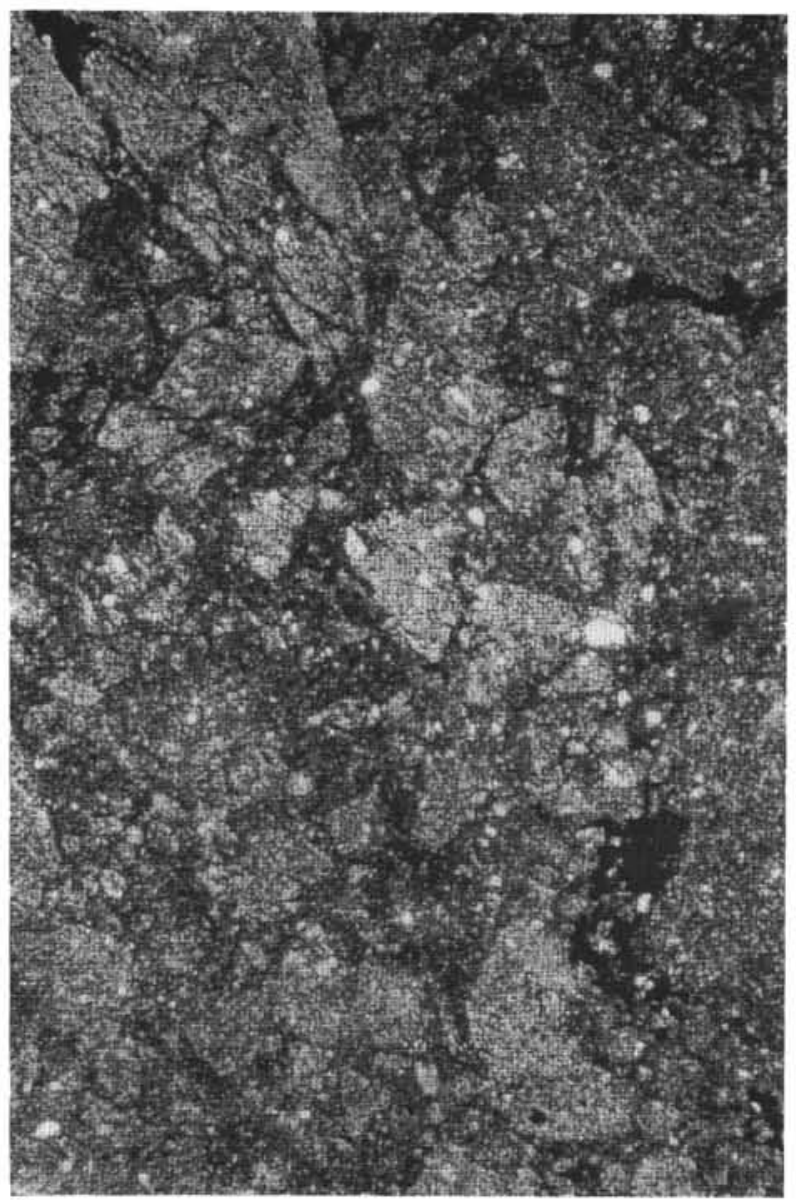

1

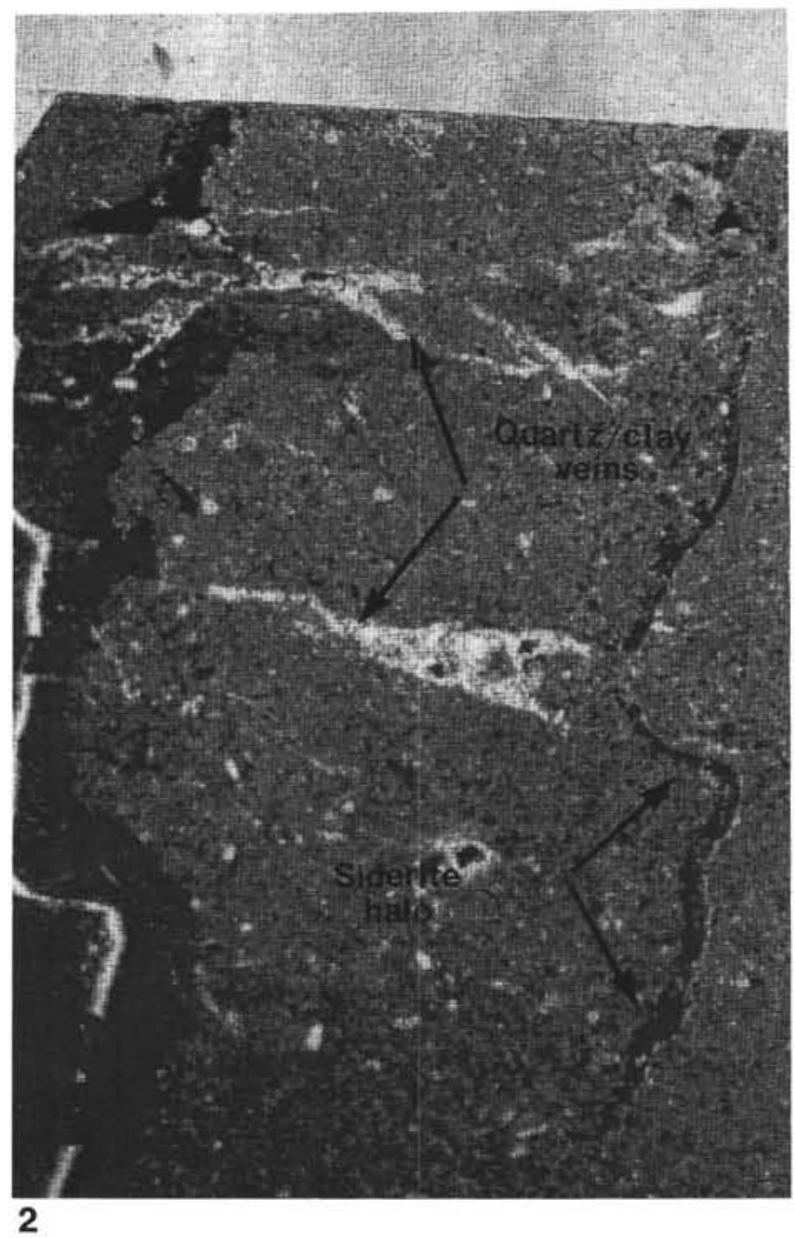

2

Plate 3. Photomicrographs of a hydrofractured siltstone from about $788 \mathrm{mbsf}$. 1. Shows the very angular shapes and the homogeneous composition of the clasts. 2. Example of a quartz/clay-rich vein. Note the presence of a siderite rim or halo in (2). The much darker halo to the right appears to be chemically similar to the matrix material; the origin of the darker appearance of this material is unknown. Table 1 shows a typical chemical analysis of the vein material in Figure 2. 

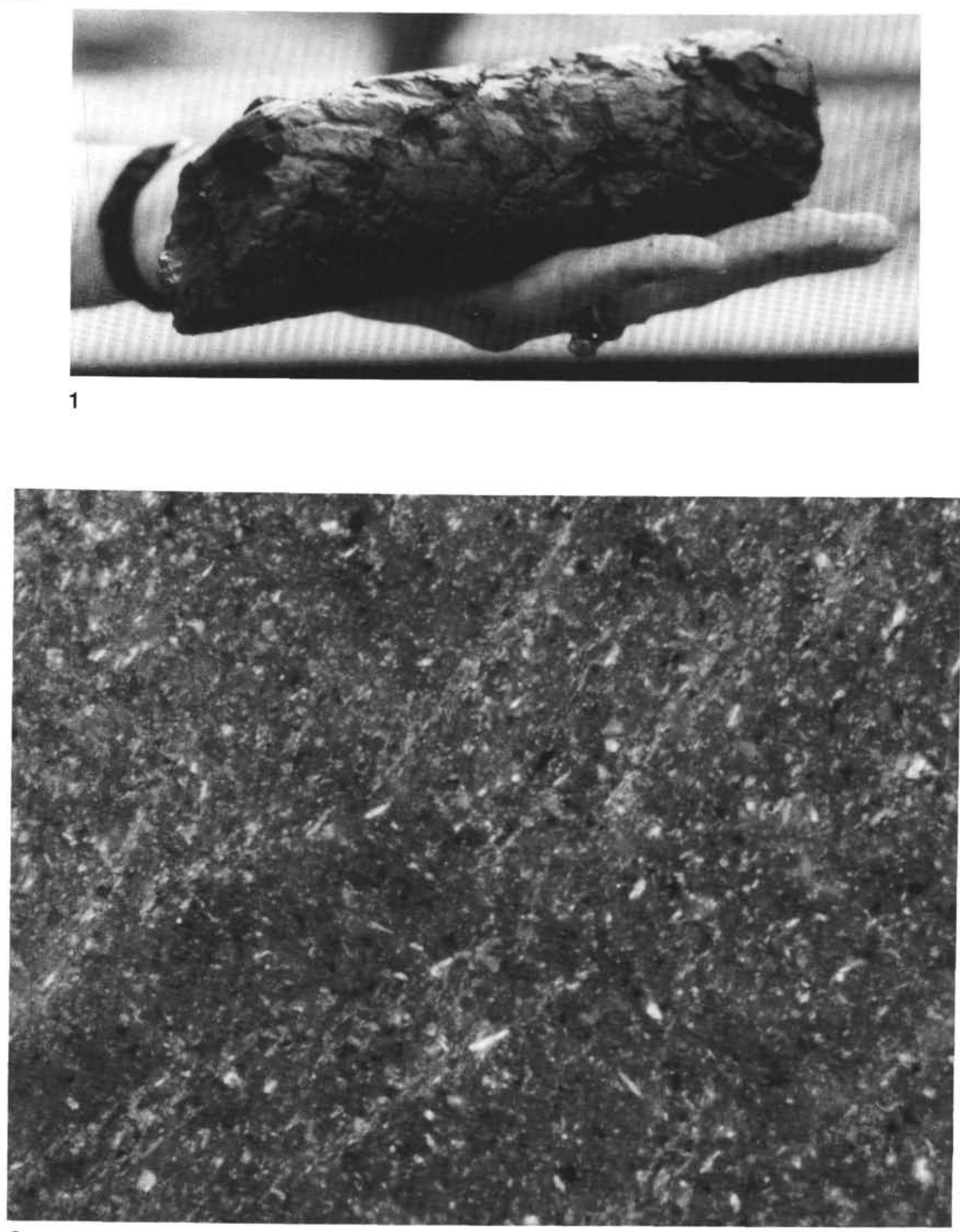

2

Plate 4. Photomicrographs of a hand sample and thin-section of siltstone from within the décollement zone. 1. Note that the siltstone is highly fractured and faulted as shown by the very rough and irregular outer surface of the sample. Despite this intense deformation, however, the sample is still cohesive. This irregular to almost anastomosing fabric is very different compared to the more planar and regular fabrics associated with the small faults and kink-like bands. 2. Photomicrograph of a siltstone from the décollement zone. Note that the décollement samples do not show the relatively thick zones of localized strain that are more typical of the faults and kink-like bands. Instead, the décollement is characterized by irregular to anastomosing zones of shear that are thin and discontinuous. 

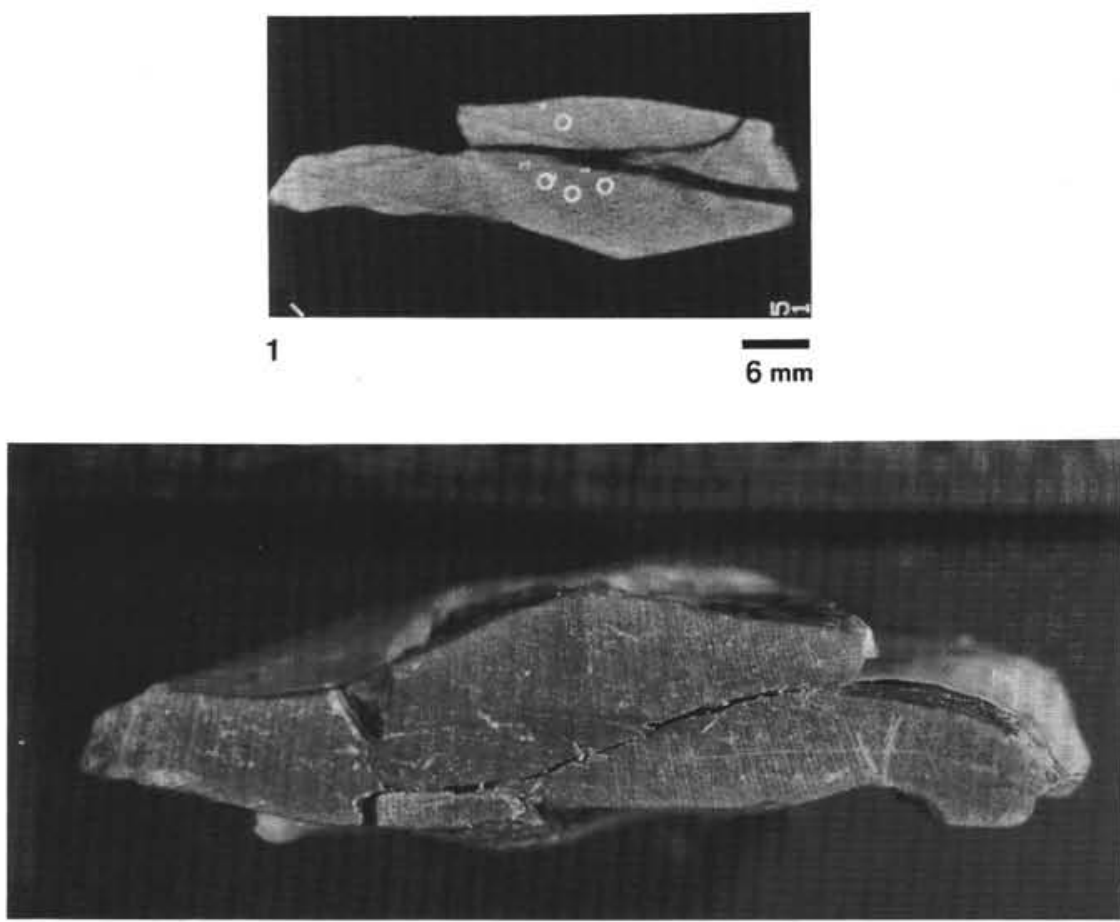

2

Plate 5. 1. Photograph showing a slabbed surface of a sample from the décollement zone. 2. CT scan of the same sample (note reversed view direction). Note the general absence of localized zones of deformation within this sample and the absence of bright or dark zones in the CT scan. The few, slightly radial bright zones in the CT scan are X-ray shadows caused by the irregular shape of the sample. 